\title{
Pharmaceuticals in Wastewater Treatment Plants: A Systematic Review on the Substances of Greatest Concern Responsible for the Development of Antimicrobial Resistance
}

\author{
Gabriele Frascaroli ${ }^{1, *} \oplus$, Deborah Reid ${ }^{1} \oplus$, Colin Hunter ${ }^{1}$, Joanne Roberts ${ }^{2}$, Karin Helwig ${ }^{1}$, Janice Spencer ${ }^{3}$ \\ and Ania Escudero ${ }^{1}$ (D) \\ 1 Department of Civil Engineering and Environmental Management, School of Computing, Engineering and \\ Built Environment, Glasgow Caledonian University, Cowcaddens Road, Glasgow G4 0BA, Scotland, UK; \\ Deborah.Reid@gcu.ac.uk (D.R.); Colin.Hunter@gcu.ac.uk (C.H.); Karin.Helwig@gcu.ac.uk (K.H.); \\ Ania.Escudero@gcu.ac.uk (A.E.) \\ 2 Department of Applied Science, School of Computing, Engineering and Built Environment, \\ Glasgow Caledonian University, Cowcaddens Road, Glasgow G4 0BA, Scotland, UK; \\ Joanne.Roberts@gcu.ac.uk \\ 3 Department of Biological and Biomedical Sciences, School of Health and Life Sciences, Glasgow Caledonian \\ University, Cowcaddens Road, Glasgow G4 0BA, Scotland, UK; Janice.Spencer@gcu.ac.uk \\ * Correspondence: Gabriele.Frascaroli@gcu.ac.uk; Tel.: +44-0141-331-8790
}

Citation: Frascaroli, G.; Reid, D.; Hunter, C.; Roberts, J.; Helwig, K.; Spencer, J.; Escudero, A.

Pharmaceuticals in Wastewater

Treatment Plants: A Systematic

Review on the Substances of Greatest

Concern Responsible for the

Development of Antimicrobial

Resistance. Appl. Sci. 2021, 11, 6670.

https://doi.org/10.3390/app11156670

Academic Editor: Nídia

Dana Lourenço

Received: 25 June 2021

Accepted: 16 July 2021

Published: 21 July 2021

Publisher's Note: MDPI stays neutra with regard to jurisdictional claims in published maps and institutional affiliations.

Copyright: (C) 2021 by the authors Licensee MDPI, Basel, Switzerland This article is an open access article distributed under the terms and conditions of the Creative Commons Attribution (CC BY) license (https:// creativecommons.org/licenses/by/ $4.0 /)$
Featured Application: The present study aimed to provide detailed and updated information valuable for managing antimicrobial resistance in wastewater treatment plants.

\begin{abstract}
In recent years, there is a growing concern about the alarming spread of antimicrobial resistance (AMR) in different environments. Increasingly, many species of bacteria, fungi and viruses are becoming immune to the most commonly used pharmaceuticals. One of the causes of the development of the resistance is the persistence of these drugs, excreted by humans, in municipal and hospital wastewater (WW). Consequently, wastewater treatment plants (WWTPs) are a primary source of antimicrobial resistance genes as novel pollutants. This systematic review sought to examine the relevant literature on pharmaceutical residues (PRs) responsible for AMR in municipal and hospital WW in order to propose a classification of the PRs of greatest concern and provide an updated source for AMR management in WWTPs. Among 546 studies collected from four databases, 18 were included in the present review. The internal and external validity of each study was assessed, and the risk of bias was evaluated on a 20-parameter basis. Results were combined in a narrative synthesis discussing influent and effluent PR concentrations at 88 WWTPs, seasonal variations, differences between hospital and municipal WW, environmental risk assessment values of antimicrobial substances and treatment facilities removal efficiencies. Among the 45 PRs responsible for AMR evaluated in this study, the antibiotics ciprofloxacin, clarithromycin, erythromycin, metronidazole, ofloxacin, sulfamethoxazole and trimethoprim constitute a considerable risk in terms of ubiquitous distribution, worrying concentrations, risk quotient values and resistance to removal treatments. Gaps in knowledge, data and information reported in this review will provide a valuable source for managing AMR in WWTPs.
\end{abstract}

Keywords: wastewater; pharmaceutical residues; antimicrobial resistance; wastewater treatment plants; occurrence; removal; environmental risk assessment; classification

\section{Introduction}

The release of pharmaceutical residues (PRs) in the environment is arousing growing concern due to the significant risks posed towards humans, animals and microbial communities. Pharmaceuticals can be only partly metabolised during therapeutic use, resulting in the excretion and release of residual fractions into the sewer [1]. Then, unchanged or in the 
form of metabolites or conjugates, PRs reach local municipal wastewater treatment plants (WWTPs) [2]. Indeed, most medications, designed to maintain their chemical structure during the course of the therapeutic treatment, may remain active in treatment facilities for a long time [3]. Many studies have shown that most drugs are significantly recalcitrant, and conventional treatment solutions for wastewater (WW) that involve the use of anaerobic/anoxic/oxic systems [4], oxidation ditches [5] or filters [6] are not designed to eliminate these compounds [7]. Consequently, a consistent flow of pharmaceuticals and their metabolites reach the aquatic environment, disturbing the ecological balance of rivers, lakes and other habitats and polluting groundwater, surface water and drinking water $[1-3,8,9]$.

Many studies have highlighted the ecological toxicity of PRs in waters environments [10-17]. However, the most immediate concern regarding the release of PRs in the aquatic environment is related to the spread of antimicrobial resistance (AMR) among several classes of pathogens, first and foremost bacteria and fungi [8,9]. Within PR compounds, antibiotics [18,19], antifungals [19-21] and personal care products [22] play a primary role in accelerating this process. Due to the selective pressure imposed on bacteria, antibiotics particularly drive the spread of antimicrobial resistance genes in environments in which there is constant contact between the microorganisms and antimicrobials [8,9]. Therefore, hospital and municipal WWTPs may be deemed potential hotspots for the development of AMR due to the high prevalence and persistence of PRs in WW teeming with bacteria and fungi.

Antimicrobial resistance undermines the efficacy of antimicrobials, causes treatments to be unsuccessful, elongates morbidity and increases mortality [23]. According to the briefing note by the Organisation for Economic Co-operation and Development (OECD) in collaboration with the European Centre for Disease Prevention and Control (ECDC), AMR causes 33,000 mortalities and costs EUR 1.1 billion per year to the health care systems in the European Union and European Economic Areas [24]. In this context, in March 2015, the European Commission considered it necessary to resort to a new mechanism to provide high-quality monitoring information on emerging pollutants in the aquatic environment. For this purpose, the Commission under the Directive 2008/105/EC [25] on Environmental Quality Standards devised a watch list with numerous substances suspected to pose a significant threat to aquatic organisms, mammals and human health via drinking water and various pathways into the food chain [26]. Among these pollutants, several antibiotics responsible for the development of AMR, such as erythromycin, clarithromycin, azithromycin and ciprofloxacin, found a place on the list.

This systematic review aimed to collate, synthesise and critically appraise all the relevant literature on the occurrence and distribution of antimicrobial substances in WW. In particular, attention has been paid to the PRs responsible for the development of the AMR, mainly antibiotics, antifungals and personal care products commonly found in municipal and hospital WWTPs. This study intended to answer the following review question: what are the main PRs relevant for the development of AMR found in hospital and municipal WWTPs? In addition to establishing the PRs of primary concern, this work attempted to define potential correlations between the presence and concentration of PRs and certain variables across studies. Emphasis has been placed on the country and season in which research was conducted, the sample source (municipal or hospital WW) and the removal performances of WWTPs. On these premises, a classification of the most harmful PRs was proposed. There is a general paucity of well-controlled studies investigating knowledge gaps in this area which this study, through constructive evaluation and criticism, hopes to address. Through due process, the present review aims to fill knowledge gaps and produce directives for future management of AMR in WWTPs.

\section{Method}

\subsection{Eligibility Criteria and Information Sources}

The literature search was conducted using four different electronic databases: Web of Science, PubMed/Medline, ProQuest and BASE on 29 January 2021. The latter two 
were included to minimise publication bias [27] and prevailing paradigm bias [28], as they contain grey literature reporting non-significant results. Regarding the search period, the year in which the European Commission established the first watch list [26] was chosen as the start date for the literature search. In order to reduce potential temporal bias [28], a search of references before 2015 was conducted to establish whether more than $50 \%$ of the literature would be excluded. If that were the case, 2008 (the year of the Directive 2008/105/EC [25]) would have been set as starting date. All the relevant references during the bibliographic databases searches were collated, regardless of the publication language. However, language bias and publication bias $[29,30]$ occurred during the article screening phase, when only studies in English, Italian or Spanish were included.

\subsection{Search Strategy}

The search started in two multidisciplinary databases most likely to yield the largest number of relevant papers: Web of Science and PubMed/Medline. Subsequently, further investigations to collect grey literature were performed using two databases that collated dissertations, theses and unpublished material: ProQuest and BASE. The key terms in the search string were established based on the review question. The terms were combined using Boolean operators and wildcards to gather all relevant studies (sensitivity) and to minimise irrelevant researches (specificity) [31]. The use of the Boolean operator "OR" for synonyms and the application of the wildcard asterisk "** increased the number of similar results, whilst the Boolean operator "AND" was used to improve the sensitivity of the search. Moreover, the sparing use of the Boolean operator "NOT" only for the title research enhanced the specificity of the search considerably.

Search string: (occurrence OR presence OR level * OR distribution OR determination) AND (pharmaceutical * OR antibiotic * OR antimicrobial *) AND (wastewater OR WW OR ("waste water" OR "waste waters") OR effluent * OR influent * OR sewage *) AND ("anti * resistance") AND ("wastewater treatment plant *" OR WWTP *) NOT ti(review) NOT ti(gene *) NOT ti(resistant) NOT ti(dairy OR swine)

(Supplementary Material, Table S3 for the strings used for each database) A clarification may be required regarding the use of the Boolean operator "NOT" in this context. A preliminary scan of the literature revealed that research of PRs in water environments could be approximately subdivided into three study areas: one concerning the presence of antimicrobials in water bodies, another dealing with removal solutions and the third investigating resistant organisms and related genes in aquatic environments. Therefore, the Boolean operator "NOT" was used to exclude all the literature belonging to the third research area. Furthermore, the use of this operator enabled the rejection of review papers and all studies that make use of dairy and swine effluents that are commonly studied separately from municipal or hospital WW. Regarding the restriction on articles about removal treatments, a cautious approach was followed since these studies often analyse also the presence of PRs.

\subsection{Selection Process}

The literature identified was uploaded in the web-based research manager RefWorks (ProQuest, Ann Arbor, MI, USA); duplicates were removed using the specific tool of the manager (a further manual check was carried out by the main reviewer (GF)). The eligibility screening of the gathered literature was applied at two different levels: title and abstract. In order to conduct a transparent sifting, a pre-set list of inclusion and exclusion eligibility criteria based on the key elements of the question was conceived for each of the two phases (Supplementary Material, Table S1). During title screening, works were excluded by observing non-rigid criteria. In the second phase, the abstract of the studies was screened using additional stricter standards (Supplementary Material, Table S1). Whilst full-text screening was aimed predominantly at bias assessment, it also served as the third phase of eligibility assessment, where this remained unclear after the first two screenings. 
The main criteria of selection and common denominator during the three screenings were based on retaining the papers dealing only with PRs responsible for AMR (Supplementary Material, Table S1). A pre-determined list of 218 PRs correlated to the development of resistance was provided in the Supplementary Material with the corresponding references (Data_extraction.xlsx, Sheet PRs List). Moreover, additional criteria were identified during the title and abstract sifting phases (see the chapter of results). The number of works rejected at each stage was reported using PRISMA flow charts (Figure 1) [32].

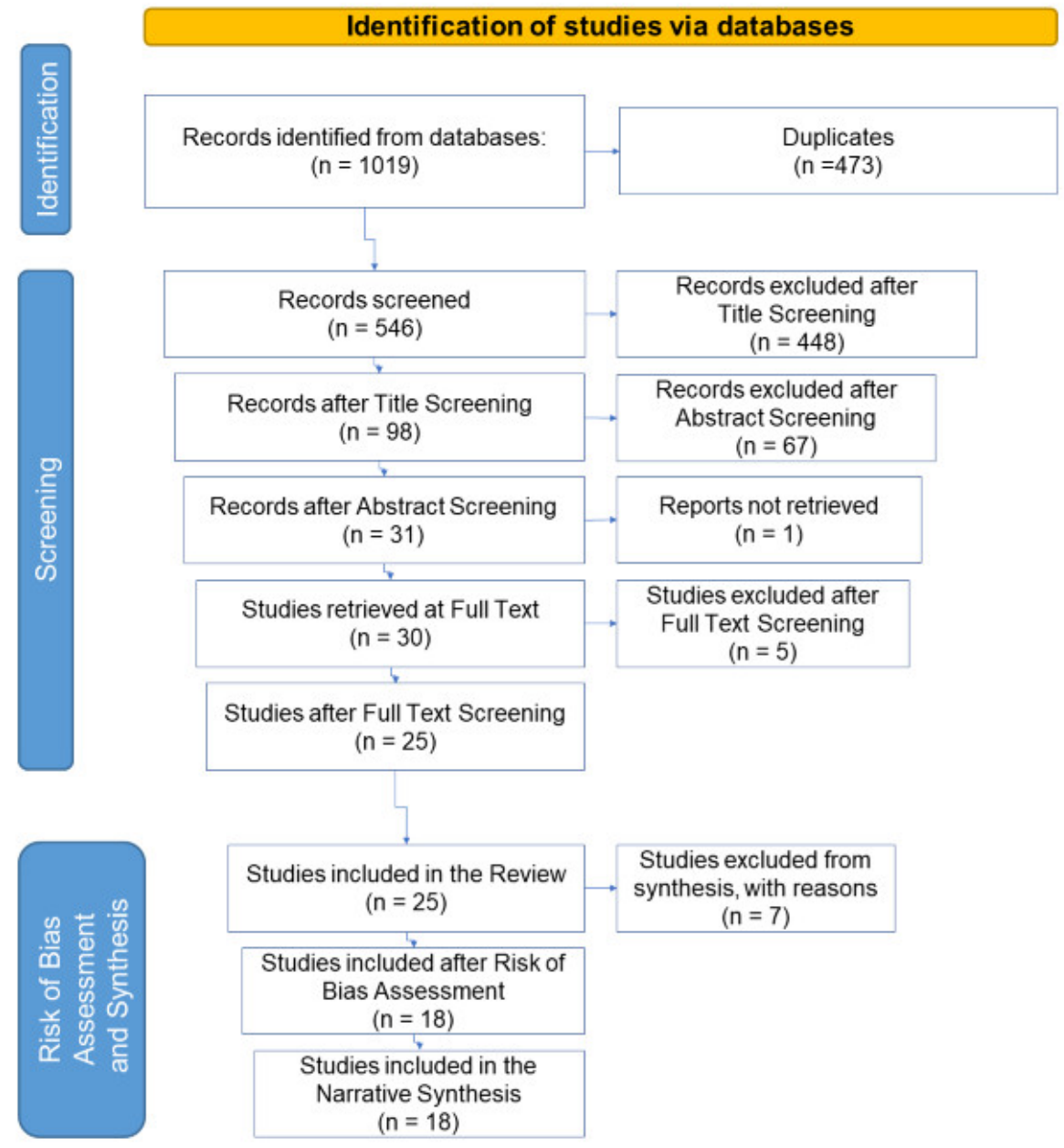

Figure 1. PRISMA flowchart representing the number of the rejected studies at each stage.

\subsection{Study Risk of Bias Assessment}

The critical appraisal of the study validity required the full-text screening of each study that passed the title and abstract screenings in order to assess to what extent evidence was free from bias (internal validity) and how the evidence was relevant to the question (external validity). A pre-set list of 20 criteria was used to evaluate the singular risk of bias for each study (Table 1). Each variable was awarded a score of $0,1,2$, according to the degree of satisfaction of the criterion. The total scores of the studies were normalised on a scale of 0 to 100 [31]. Works that failed to meet the criteria were considered at "high risk of bias" (scores less than 33), whilst studies with an adequate methodology to protect against bias were deemed at "low risk of bias" (scores higher than 67) [33]; a third category "medium risk of bias" (studies with scores between 33 and 67) was conceived to avoid a rigid dichotomy. Works considered at high risk of bias were excluded from the data coding phase. 
Table 1. Pre-set list of bias assessment for internal and external validity.

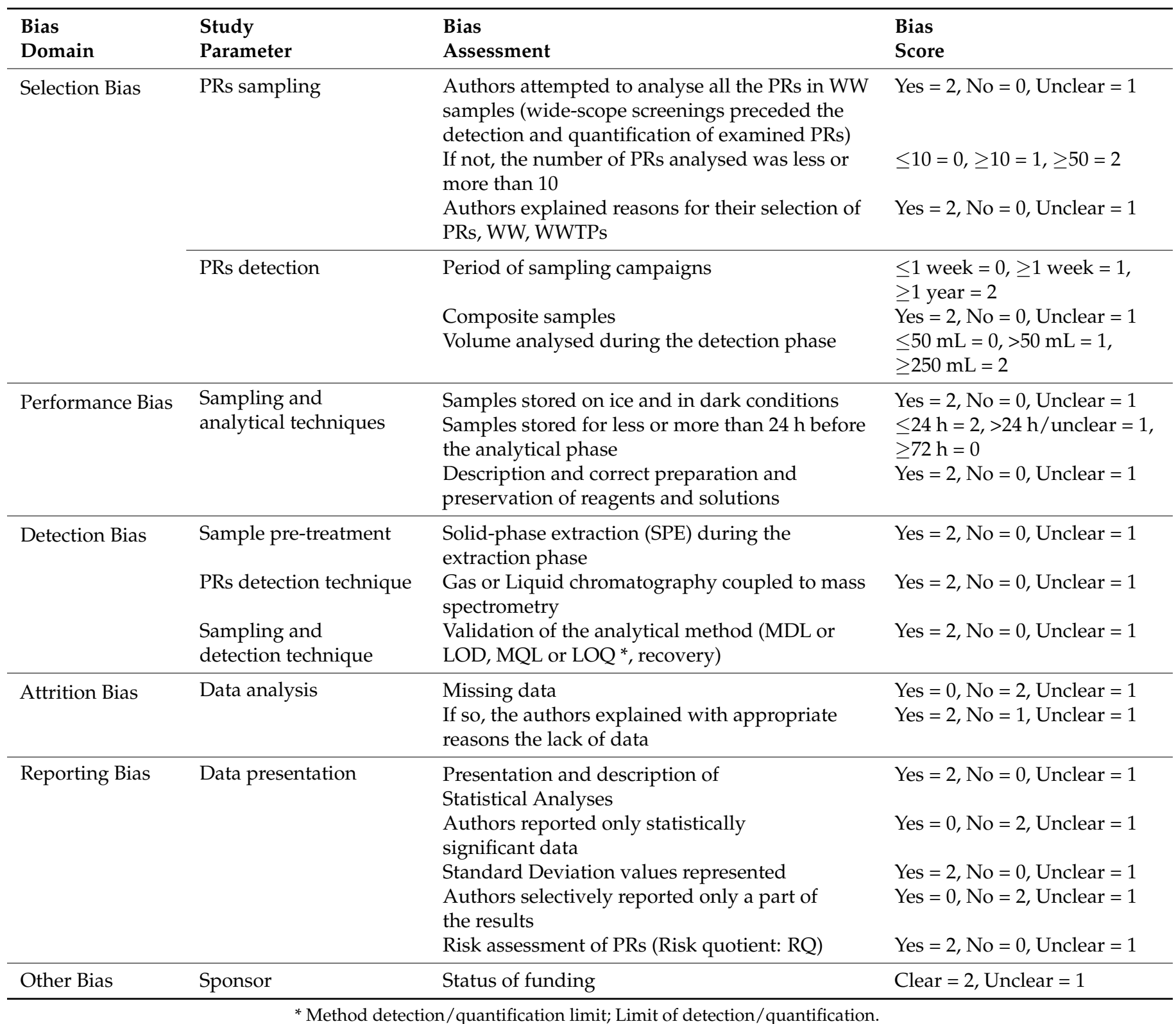

External validity was assessed by considering to what extent the information of the studies included in the review fulfilled the review question and whether the answers to the query could be applied directly into real-world conditions. Emphasis was given to specific information such as the environmental risk assessment: studies that contextualised the presence of PRs with the risk posed to the environment were particularly informative and considered more significant than investigations that give a simple overview of the PRs concentrations. The same applied to analyses that made use of solid-phase extraction or direct injection, a technique that increases the detection capacity of a study considerably [8]. Moreover, the number of examined treatment facilities or the size of samples were taken into account to assess the external validity.

\subsection{Data Collection and Synthesis}

Using a pre-set list of potential information about the significant characteristics and results of studies (Supplementary Material, Table S2), relevant data were extracted from the validated studies. Results were combined in a narrative synthesis subdivided into five sections that comment on main findings, namely the PR concentrations in influents 
and effluents of the treatment facilities, seasonal variations of PRs, differences between hospital and municipal WW, environmental risk assessment of the antimicrobial substances and removal efficiencies of the plants (Supplementary Material, Data_extraction.xlsx). Sub-group analyses were performed to investigate significant differences between PR concentrations in effluents and influents, or municipal and hospital WWTPs, and between seasons. Statistical analyses were performed using Microsoft Excel 2016 (Microsoft Corporation, Washington, DC, USA) and SPSS Statistics V26.0 (IBM SPSS Statistics, Armonk, NY, USA). The independent $t$-test, based on Levene's Test for equality of variances, was used to determine differences in PR concentrations between effluents and influents and municipal and hospital WWTPs. One-way ANOVA, following the Bonferroni correction method, was used to determine differences between seasons.

\section{Results}

\subsection{Study Selection and Study Characteristics}

The search for literature published between March 2015 and January 2021 yielded 1019 references across the four electronic databases (Table 2). The initial search in ProQuest returned 2544 references, a number that was considered excessive and difficult to manage. Therefore, a more specific analysis was conducted to search for the keywords only within the title and abstract; this enabled a reduction to 618 of the references. More than $65 \%$ of the literature returned was published after 2015. This is likely to indicate that the problem related to the presence of PRs responsible for AMR discharged in WWTPs has come only recently to researchers' attention. On the other hand, 35\% of the literature was excluded from this review, aware of studying a recent and ever-changing problem (the first paper relevant to the question is dated 1992).

Table 2. Results of the string search in four databases.

\begin{tabular}{lll}
\hline \multirow{2}{*}{ Database } & No. of References after 2015 & No. of References before $\mathbf{2 0 1 5}$ \\
\cline { 2 - 3 } & (Percentage) & (Percentage), Year of the First Publication \\
\hline Web of Science & $170(68.0 \%)$ & $80(32.0 \%), 2000$ \\
PubMed/Medline & $195(62.3 \%)$ & $118(37.7 \%), 2001$ \\
ProQuest 1st search & $2544(66.5 \%)$ & $1280(33.5 \%), 1992$ \\
ProQuest 2st search & $618(68.4 \%)$ & $286(31.6 \%), 1992$ \\
BASE & $36(66.7 \%)$ & $18(33.3 \%), 2009$ \\
Total & $\mathbf{1 0 1 9}($ mean $67.0 \%)$ & $502($ mean $33.0 \%)$ \\
\hline
\end{tabular}

Of the 1019 references collected during the search phase, the duplicates finder of RefWorks identified 246 copies to be removed (724 remainings); a further manual screening enabled to exclude another 227 references (546 remainings). The 546 remaining references were subjected to title screening. Following the selection criteria set out in Table S1, 448 references were excluded:

- 17 did not meet the criteria for the key element PRs since dealing with non-pharmaceutical compounds or PRs non-relevant to AMR (Supplementary Material, Data_extraction.xlsx, Sheet PRs List).

- 29 analysed surface water, drinking water or sludge samples and therefore did not satisfy the requirements for WW.

- 256 were off-topic since they investigated specifically resistant organisms or removal treatments.

- $\quad 17$ were overviews, reviews, global perspectives or insights.

- 2 studies written in Portuguese, a language not included in the list (Table S1).

- 127 were considered not relevant for other reasons not covered in the pre-set criteria: these dealt with metagenomic or metatranscriptomic analyses, bacterial population dynamics, disinfection systems, phages or viruses in WW, bacteria in the aerosol or indicators of pollution. 
Ninety-eight references passed the title screening. Of these, 68 were rejected following the abstract inclusion and exclusion criteria:

- 7 focused on one PR only (triclosan, amoxicillin, vancomycin) and therefore did not meet the requirements for the key element $\mathrm{PH}$.

- 5 investigated the PRs concentrations in surface water and not in WW.

- 1 analysed the samples deriving from the WW of a nursing home and not from a municipal or hospital WWTPs.

- 27 did not comply with the criteria defined for the topic, as they investigated resistant bacteria or genes, or new removal treatments in small conditions.

- 13 were reviews or similar.

Moreover,

- 1 was written in Slovenian, a language not included in the list (Table S1).

- 1 was unavailable.

- 13 were excluded based on criteria set during the screening phase (metagenomic or metatranscriptomic, the dynamic of bacterial populations, disinfection systems, phages or virus in WW, bacteria in the aerosol, and indicators of pollutions).

After the title and abstract screening, the eligibility status of 5 studies remained unclear and required the full-text screening, that were all excluded:

- 2 papers investigated the presence of PRs in WW of pharmaceutical factories, regarded as insignificant since the concentrations and types of antimicrobial substances identified at such plants are not comparable with PRs discharges of hospital or municipal facilities (subject of discussion in this review). Moreover, although pharmaceutical factories are a hotspot for the presence of PRs, usually, antimicrobial substances in their treatment facilities, these are largely and efficiently removed [34].

- 1 study examined sludge and not aqueous WW samples.

- 1 researched antimicrobial substances in biofilms in water environments after WW discharge.

- 1 study developed an analytical method for the quantification of fluoroquinolones antibiotics in WW.

The remaining 25 references moved to the critical appraisal phase.

\subsection{Risk of Bias in Studies}

The 25 consisted of twenty-four journal articles and one thesis (which required the screening of the chapters relevant to this review). These studies were scrutinised entirely to extract the information related to the criteria for assessing internal validity. Table 3 shows the total score for each work. A number from 1 to 25 was assigned to the studies. A file with the list of references and scores for each criterion is provided in the supplementary material (Data_extraction.xlsx, Sheet Risk of Bias).

Table 3. Bias assessment for internal validity for each study.

\begin{tabular}{cccccccccccccc}
\hline Study & 1 & 2 & 3 & 4 & 5 & 6 & 7 & 8 & 9 & 10 & 11 & 12 & 13 \\
Score & 67.5 & 45 & 77.5 & 62.5 & 60 & 70 & 65 & 65 & 75 & 65 & 55 & 65 & 62.5 \\
\hline Study & 14 & 15 & 16 & 17 & 18 & 19 & 20 & 21 & 22 & 23 & 24 & 25 & \\
Score & 70 & 55 & 52.5 & 60 & 70 & 45 & 45 & 77.5 & 65 & 80 & 70 & 52.5 & \\
\hline
\end{tabular}

Studies at high risk of bias (score $<33$ ): 0 ; Studies at medium risk of bias $(33 \leq$ score $\leq 66)$ : 16 ; Studies at low risk of bias (score > 66): 9 .

The internal validity assessment showed that no study was at high risk of bias, and the average score for protection from bias stood at 63 points. However, after the appraisal stage, several critical observations arose. One of the primary considerations concerns the paucity of studies that developed wide-scope target screenings before starting the search of PRs of interest. Indeed, only three research groups carried on extensive analyses to assess all potential antimicrobial substances in WW $[5,12,35]$. Related to this issue, a common 
trait among studies is the lack of proper explanations on the selection of PRs for analysis, although there are numerous ways to approach this search. For instance, Moslah et al. started with a forensic investigation on the presence of illicit drugs in urine [36]. On the other hand, Giebułtowicz and colleagues based the PRs selection on sales data for antimicrobial substances in Poland [13]. Similarly, Dalahmeh et al. approached the search with a pharmacy survey on the most prescribed and sold PRs [6].

The ambiguities in the presentation and description of statistical analyses represent another critical aspect. For example, while it is true that more than half of the studies $(66 \%)$ reported standard deviation values, it is also true that only $11 \%$ adequately presented and described the statistical method used to obtain those values.

On the other hand, several precautions taken by authors during the samplings and the detection phases helped minimise the risk of bias in their studies. Almost all the sampling campaigns gathered composite samples, and almost all stored them appropriately in dark and cool conditions. Furthermore, apart from the simplified SPE procedure proposed by Afonso-Olivares and colleagues [37], all research teams used traditional online or offline SPE. Finally, in twenty studies, detection of PRs was carried out through LC (HPLC, UPLC) coupled to MS techniques.

Considering the above and the scores obtained, the exclusion of studies based on external validity assessment could not be pursued. However, to enhance the homogeneity of the literature addressed in this review and to enable all quantitative analyses proposed, six studies were rejected since:

- 1 did not specify the dates of the sampling campaign. This information is essential to compare studies on seasonal variations of PRs in WW [38].

- 6 showed the PRs concentrations in bar charts only and did not provide tables with single concentration values for each PR and sampling point.

Before excluding these studies, an attempt was made to obtain the required information by contacting authors by email, but this was unsuccessful. The number of the rejected works at each stage was reported by PRISMA flow charts (Figure 1).

\subsection{Characteristics of Studies}

Within the eighteen studies included in the review, 45 different PRs were detected. More than half of the studies (ten) analysed 10 or more different antimicrobial substances responsible for AMR. A pattern of considerable variability between the studies emerged, especially for what concerns their research objects and outcomes. This erraticism is particularly marked if we consider the concentrations of the antimicrobial compounds in effluents, for instance. By way of illustration, trimethoprim concentrations ranged from $8.7 \mathrm{ng} / \mathrm{L}$ [12] to 26,100 [6], sulfamethoxazole levels from $1 \mathrm{ng} / \mathrm{L}$ [35] to 21,400 [6] and ofloxacin oscillated between $9.3 \mathrm{ng} / \mathrm{L}$ [39] and 200,000 [11]. These, and other differences related to the PRs removal efficiency of WWTPs, may depend on the variability between the treatment processes $[5,35,39]$, the characteristics of WWTPs [36,39], as well the typology of WW (municipal or hospital) [16,35].

A slight variability was also observed regarding the subject areas covered by the studies and relevant to this review (Figure 2). Fourteen articles measured the presence of PRs in WWTPs influents in addition to the characterisation of the effluents. Six assessed the removal efficiencies of investigated treatment facilities, and eight of the studies correlated the PRs concentrations in effluents with the risk that the antimicrobial substances posed to the environment. Finally, only two papers out of eighteen investigated PRs both in hospital and municipal WW, whereas two others investigated both municipal and hospital WWTPs. 

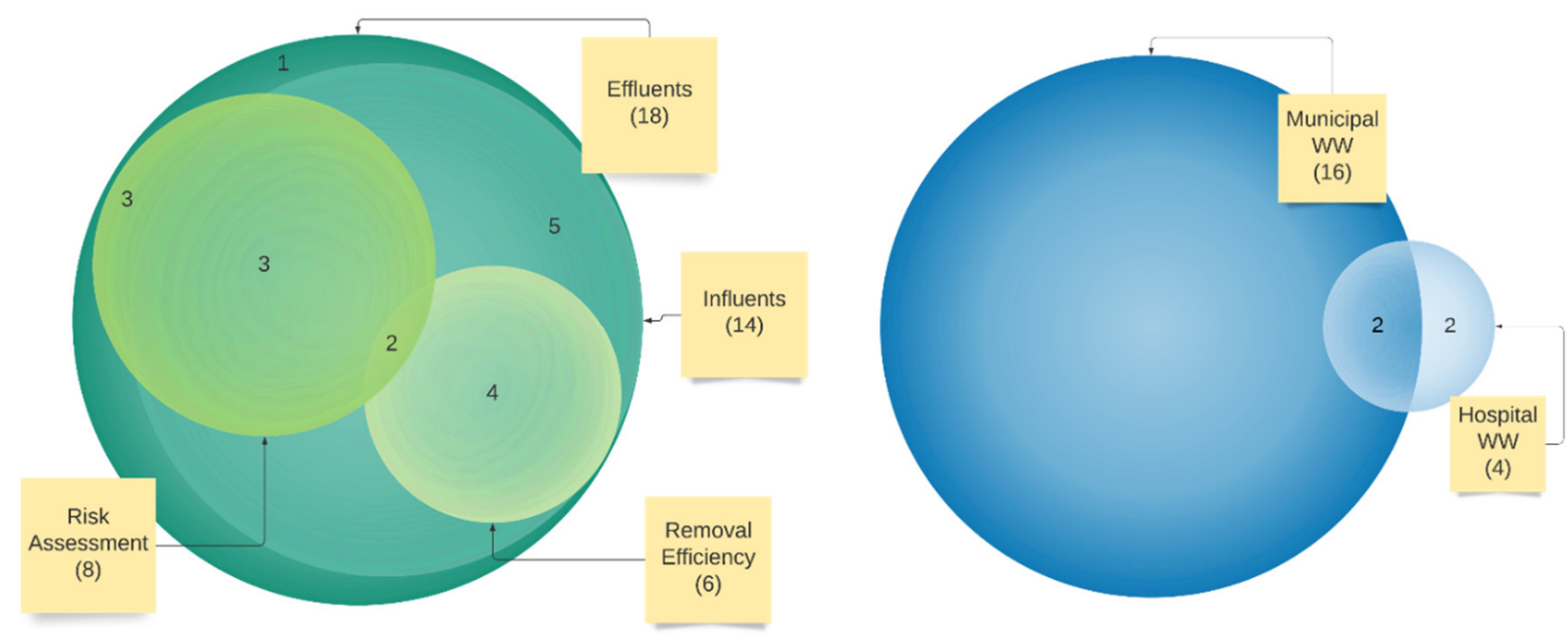

Figure 2. Subject areas of the 18 studies that were scrutinised in the data extraction phase. (Source: Lucidchart).

In total, the selected literature appraised in this study considered 88 WWTPs (75 municipal treatment facilities and 13 dealing with hospital WW) within 25 countries in three continents (Europe, Africa, Asia) (Figure 3). Unexpectedly, no articles about the presence of PRs in North or South America passed the search screening phase. That may be explained by the different approaches to the research that countries conventionally follow in this field. As a matter of fact, Canadian and US studies usually cover wide-ranging reviews on the hazards posed by AMR [40-42] or deal with the genomic and transcriptomic facets of the resistance of bacteria [43,44]. Moreover, the interest in drug-resistant pathogenic microorganisms is widely shared in South America, as proven by several papers published in Brazil [45-47]. On the other hand, this thematic seems not to appeal to large countries such as Russia or Australia.

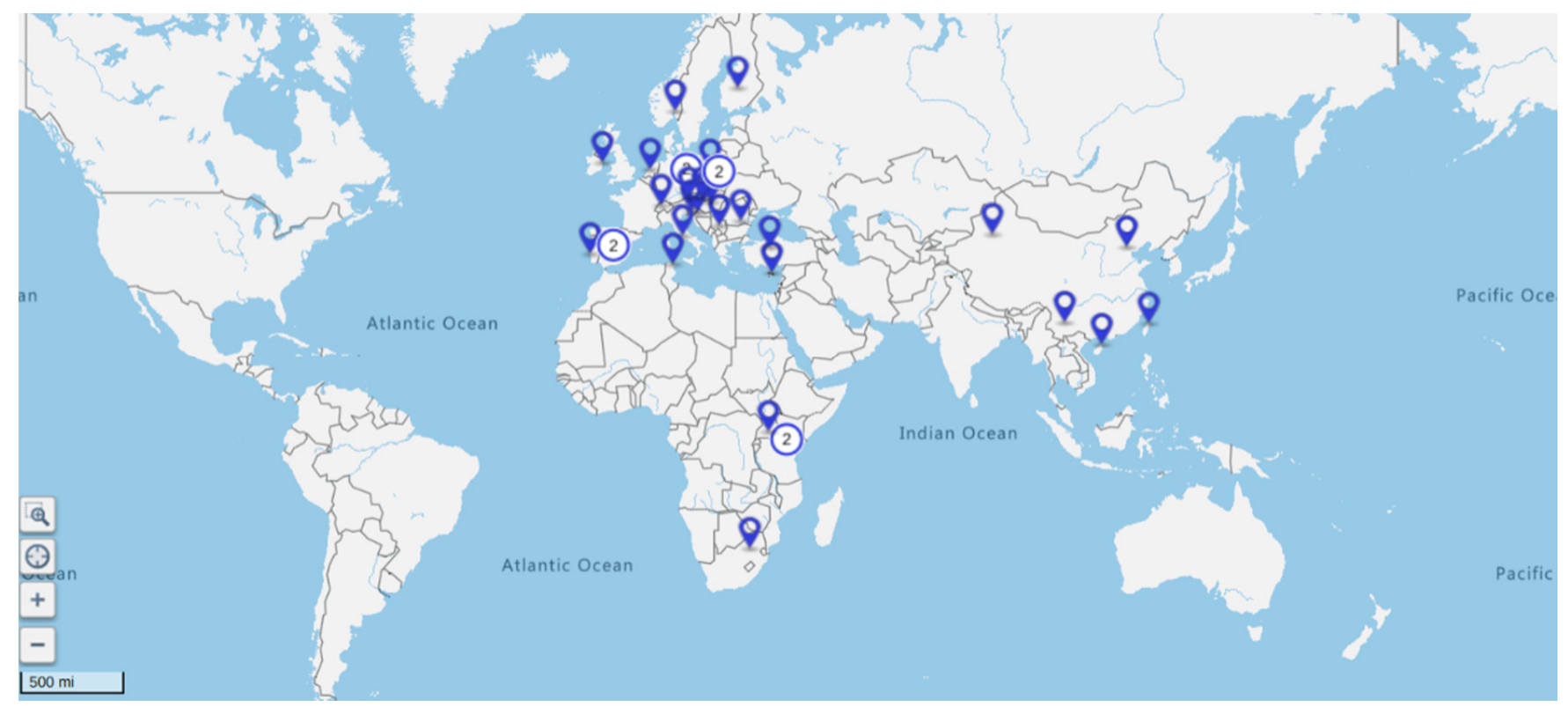

(a)

Figure 3. Cont. 


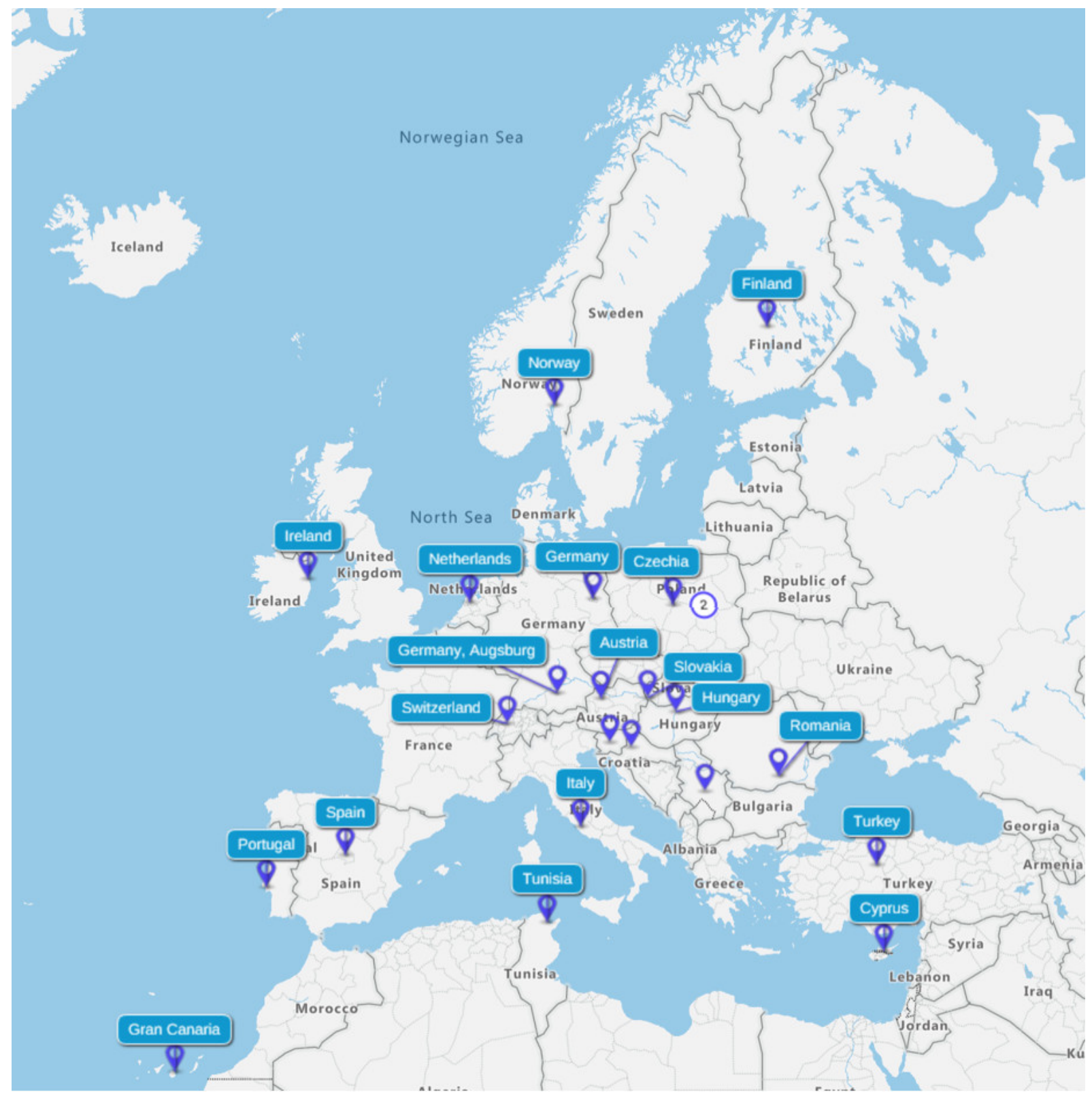

(b)

Figure 3. The twenty-five countries covered by the literature (a) and detail on Europe (b). (Source: eSpatial).

\section{Discussion}

\subsection{Concentrations of Pharmaceuticals in Influents and Effluents Wastewater}

Most authors employed high-throughput techniques for the extraction and detection stages during the analytical phase of the research. Indeed, all the analyses made use of SPE for the isolation of the compounds. Out of eighteen studies, three used Online-SPE [5,16,39], two employed automated extraction systems [12,35], and one proposed a simplified SPE procedure [37]. For what concerns the identification and quantification of PRs, all the studies, except for two $[16,48]$, combined liquid chromatography techniques (twelve HPLC and four UPLC) with mass spectrometry.

Among the 218 PRs ascertained responsible for the development of AMR (Supplementary Material, Data_extraction.xlsx, Sheet PRs List), 45 were detected within the eighteen studies in 88 different WWTPs. The PRs belong to 16 different classes of antibiotics, antifungals, antiprotozoals and antimalarials. Among them, quinolones, sulfonamides, macrolides, tetracyclines and azoles represent $69 \%$ of all the PRs reported by the authors 
(Figure 4). Seven of those, namely ciprofloxacin, clarithromycin, erythromycin, metronidazole, ofloxacin, sulfamethoxazole and trimethoprim, occurred in more than $50 \%$ of studies (nine). In particular, ciprofloxacin, sulfamethoxazole and trimethoprim were detected in more than $75 \%$ of papers (fourteen). Azithromycin, clindamycin, norfloxacin, oxytetracycline, roxithromycin, sulfadiazine and tetracycline occurred within five and nine studies $(25-50 \%)$.

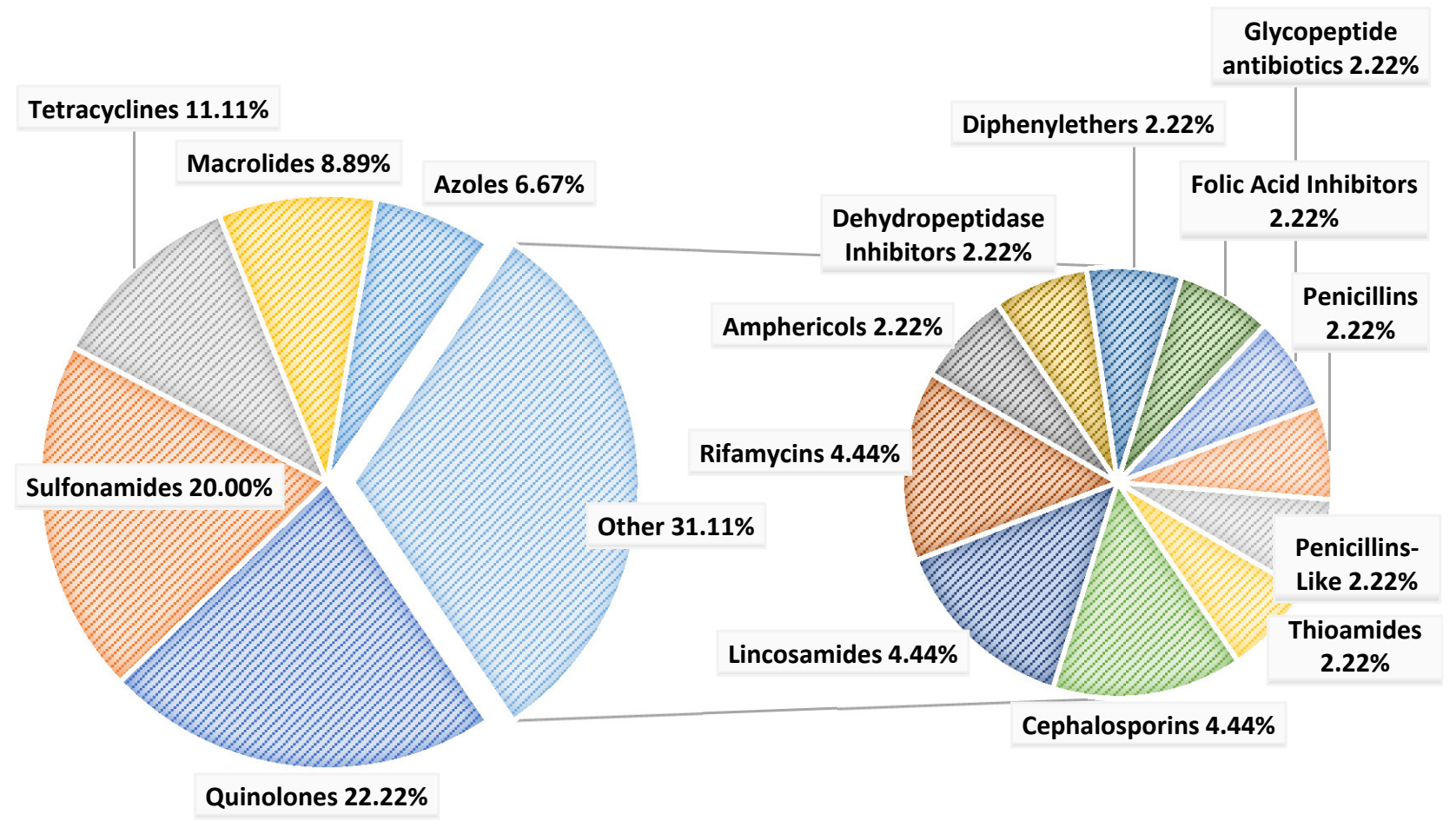

Figure 4. Sixteen different classes of PRs detected among studies.

The influent concentration of the most common PRs occurring in 46 WWTPs was investigated (Table 4). Only compounds shared in more than four studies (out of fourteen) were considered in this analysis. It should be pointed out that a constraint in this comparative study lies in that the studies dealt with different limits of quantification.

Table 4. Max average concentrations and means (ng/L) of the PRs detected in more than a quarter of the studies in the influent of 46 WWTPs.

\begin{tabular}{lllll}
\hline Pharmaceutical & $\begin{array}{l}\text { Max. Average Conc. (ng/L) } \\
\text { Detected in Influents }\end{array}$ & City (Country) & Ref. & Mean across Studies (ng/L) \\
\hline Azithromycin & 115,413 & Sanya City (China) & {$[17]$} & 12,856 \\
Ciprofloxacin & 88,012 & Durban (South Africa) & {$[39]$} & 8706 \\
Clarithromycin & 6917 & Sanya City (China) & {$[17]$} & 732 \\
Clindamycin & 134 & Warsaw (Poland) & {$[13]$} & 53 \\
Erythromycin & 1193 & Choutrana (Tunisia) & {$[36]$} & 295 \\
Metronidazole & 20,656 & Durban (South Africa) & {$[39]$} & 2002 \\
Norfloxacin & 2800 & Kangemi (Kenya) & {$[15]$} & 454 \\
Ofloxacin & 5742 & Durban (South Africa) & {$[39]$} & 764 \\
Oxytetracycline & 1531 & Sanya City (China) & {$[17]$} & 241 \\
Roxithromycin & 19,135 & Sanya City (China) & {$[17]$} & 2045 \\
Sulfadiazine & 574 & Xinjiang (China) & {$[48], \mathrm{H}$} & 179 \\
Sulfamethoxazole & 49,300 & Machakos (Kenya) & {$[15]$} & 4434 \\
Tetracycline & 374 & Xinjiang (China) & {$[48], \mathrm{H}$} & 115 \\
Trimethoprim & 8430 & Kampala (Uganda) & {$[6]$} & 982 \\
\hline
\end{tabular}


Within the fourteen studies that assessed influent WW, authors reported worryingly high levels for several compounds. The highest concentrations were reported in Durban (South Africa) and Machakos (Kenya) for ciprofloxacin and sulfamethoxazole, respectively, at 88,012 and 49,300 ng/L [15,39]. Ren et al. reported an alarming high level of 100,000 ng/L of azithromycin in a WWTP in Sanya City (China) during the high tourist seasons [17]. The highest concentrations of trimethoprim $(8430 \mathrm{ng} / \mathrm{L})$, norfloxacin $(2800 \mathrm{ng} / \mathrm{L})$ and erythromycin (1193 ng/L) were detected in Choutrana (Tunisia), Kangemi (Kenya) and Kampala (Uganda), respectively $[6,15,36]$. Finally, a clindamycin concentration nearly three times higher than the mean across the studies was reported in a treatment facility in Warsaw (Poland) [13].

When looking at the highest PRs concentrations in the effluents of the 88 WWTPs (Table 5), sulfamethoxazole, ofloxacin and erythromycin were detected in more than $61 \%$ of studies (eleven) as the substances with the highest concentrations among the other antimicrobial substances. In studies in which sulfamethoxazole represented the most abundant $\mathrm{PH}$, authors reported values ranging from 275 to $21,400 \mathrm{ng} / \mathrm{L}[13,15,37,49]$, all detected in municipal WW samples. Yilmaz and colleagues observed an ofloxacin concentration of $3051 \mathrm{ng} / \mathrm{L}$ in effluents from a WWTP in Ljubljana (Slovenia) [11]. Similarly, Moslah et al. reported an amount of ofloxacin equal to $648 \mathrm{ng} / \mathrm{L}$ in municipal WW effluents in Tunis (Tunisia) [36]. Moreover, erythromycin presented concentrations between 40 and $1187 \mathrm{ng} / \mathrm{L}$ in studies in which this compound was found in the highest concentrations; all were observed in municipal WW [35,36,50]. Although reported in thirteen studies out of the eighteen, trimethoprim was the compound found in the lowest concentrations in four of these $(0.01-100 \mathrm{ng} / \mathrm{L})[11,15,36,37]$.

Table 5. List of 45 pharmaceuticals detected in 88 WWTPs, investigated in the eighteen studies. Maximum and minimum average concentrations and means were reported and expressed in $\mathrm{ng} / \mathrm{L}$.

\begin{tabular}{|c|c|c|c|c|c|}
\hline Class & Pharmaceutical & $\begin{array}{l}\text { No. of Studies in } \\
\text { Which the PR } \\
\text { Was Detected } \\
\text { (\% of the Total) }\end{array}$ & $\begin{array}{l}\text { Max. Average Conc. } \\
\text { (ng/L) Detected } \\
\text { in Effluents }\end{array}$ & $\begin{array}{l}\text { Min. Average Conc. } \\
\text { (ng/L) Detected } \\
\text { in Effluents * }\end{array}$ & $\begin{array}{l}\text { Mean across } \\
\text { Studies (ng/L) }\end{array}$ \\
\hline Amphericols & Chloramphenicol & $3(16.7)$ & 97 [12] & $5.9[50]$ & 50 \\
\hline \multirow[t]{3}{*}{ Azoles } & Fluconazole & $3(16.7)$ & $170[5]$ & 3 [35], H & 73 \\
\hline & Metronidazole & $10(55.6)$ & 3000 [11], H & $1.2[39]$ & 330 \\
\hline & Tinidazole & $1(5.6)$ & 12 [49] & $9.1[49]$ & 10 \\
\hline \multirow[t]{2}{*}{ Cephalosporins } & Cefalexin & $2(11.1)$ & $308[10]$ & $5.0[35]$ & 117 \\
\hline & Ceftazidime & $1(5.6)$ & $1600[11], \mathrm{H}$ & 1600 [11], H & 1600 \\
\hline $\begin{array}{l}\text { Dehydropeptidase } \\
\text { Inhibitors }\end{array}$ & Cilastatin & $1(5.6)$ & 4100 [11] & $4100[11], \mathrm{H}$ & 4100 \\
\hline Diphenylethers & Triclosan & $1(5.6)$ & 7.4 [12] & 0.9 [12] & 4.2 \\
\hline $\begin{array}{l}\text { Folic Acid } \\
\text { Inhibitors }\end{array}$ & Trimethoprim & $14(77.8)$ & $26,100[6]$ & $1.6[17]$ & 1979 \\
\hline $\begin{array}{l}\text { Glycopeptide } \\
\text { antibiotics }\end{array}$ & Vancomycin & $2(11.1)$ & 162 [13] & 81 [14] & 119 \\
\hline \multirow[t]{2}{*}{ Lincosamides } & Clindamycin & $5(27.8)$ & $290[13]$ & 0.5 [39] & 71 \\
\hline & Lincomycin & $4(22.2)$ & $56[13]$ & $1.5[12]$ & 26 \\
\hline \multirow[t]{4}{*}{ Macrolides } & Azithromycin & $8(44.4)$ & $56,666[17]$ & 0.1 [39] & 4387 \\
\hline & Clarithromycin & $12(66.7)$ & $15,000[11], \mathrm{H}$ & $0.2[39]$ & 750 \\
\hline & Erythromycin & $11(61.1)$ & $1187[36]$ & 0.1 [39] & 304 \\
\hline & Roxithromycin & $6(33.3)$ & 6272 [17] & $3.6[17]$ & 882 \\
\hline Penicillins & Ampicillin & $4(22.2)$ & 790 [16], H & $60[16]$ & 254 \\
\hline Penicillins-Like & Amoxicillin & $4(22.2)$ & $1600[15]$ & 40 [12] & 463 \\
\hline
\end{tabular}


Table 5. Cont.

\begin{tabular}{|c|c|c|c|c|c|}
\hline Class & Pharmaceutical & $\begin{array}{l}\text { No. of Studies in } \\
\text { Which the PR } \\
\text { Was Detected } \\
\text { (\% of the Total) }\end{array}$ & $\begin{array}{l}\text { Max. Average Conc. } \\
\text { (ng/L) Detected } \\
\text { in Effluents }\end{array}$ & $\begin{array}{l}\text { Min. Average Conc. } \\
\text { (ng/L) Detected } \\
\text { in Effluents* }\end{array}$ & $\begin{array}{l}\text { Mean across } \\
\text { Studies (ng/L) }\end{array}$ \\
\hline \multirow[t]{10}{*}{ Quinolones } & Ciprofloxacin & $15(83.3)$ & $24,000[11], \mathrm{H}$ & $0.6[17]$ & 1137 \\
\hline & Flumequine & $3(16.7)$ & $63[12]$ & $3.0[35], \mathrm{H}$ & 28 \\
\hline & Lomefloxacin & $2(11.1)$ & 4.6 [17] & 0.3 [17] & 1.6 \\
\hline & Marbofloxacin & $1(5.6)$ & $<\operatorname{LOD}[35]$ & $<\operatorname{LOD}[35]$ & $<\mathrm{LOD}$ \\
\hline & Nalidixic Acid & $2(11.1)$ & $50[10]$ & $7.8[49]$ & 24 \\
\hline & Norfloxacin & $8(44.4)$ & 2900 [15] & $0.5[39]$ & 221 \\
\hline & Ofloxacin & $12(66.7)$ & $200,000[11], \mathrm{H}^{* *}$ & $2.7[17]$ & 7405 \\
\hline & Oxolinic Acid & $3(16.7)$ & $60[12]$ & $4.6[12]$ & 19 \\
\hline & Sparfloxacin & $1(5.6)$ & $<\operatorname{LOD}[6]$ & $<\operatorname{LOD}[6]$ & $<\mathrm{LOD}$ \\
\hline & Sulfamerazine & $1(5.6)$ & 28 [17] & $0.3[17]$ & 8.0 \\
\hline \multirow[t]{2}{*}{ Rifamycins } & Rifampicin & $1(5.6)$ & $2.9[13]$ & $2.9[13]$ & 2.9 \\
\hline & Rifaximin & $2(11.1)$ & 12 [12] & $3.8[12]$ & 7.0 \\
\hline \multirow[t]{9}{*}{ Sulfonamides } & Sulfadiazine & $8(44.4)$ & 373 [48], H & $0.8[17]$ & 53 \\
\hline & Sulfadimidine & $2(11.1)$ & $106[12]$ & $3[12]$ & 54 \\
\hline & Sulfadoxine & $1(5.6)$ & $<\operatorname{LOD}[35]$ & $<\operatorname{LOD}[35]$ & $<\mathrm{LOD}$ \\
\hline & Sulfamethazine & $4(22.2)$ & $21[17]$ & $0.8[17]$ & 7.0 \\
\hline & Sulfamethizole & $2(11.1)$ & 19 [17] & $0.04[23]$ & 3.6 \\
\hline & Sulfamethoxazole & $16(88.9)$ & $21,400[15]$ & $1.0[35], \mathrm{H}$ & 1217 \\
\hline & Sulfamoxole & $1(5.6)$ & $<\operatorname{LOD}[35]$ & $<\operatorname{LOD}[35]$ & $<\mathrm{LOD}$ \\
\hline & Sulfathiazole & $1(5.6)$ & $138[17]$ & $0.9[17]$ & 21 \\
\hline & Sulfisoxazole & $1(5.6)$ & 20 [17] & $1.6[17]$ & 8.1 \\
\hline \multirow[t]{5}{*}{ Tetracyclines } & Chlortetracycline & $2(11.1)$ & $12[48], \mathrm{H}$ & 0.5 [17] & 4.0 \\
\hline & Doxycycline & $3(16.7)$ & $1500[15]$ & $0.4[17]$ & 191 \\
\hline & Minocycline & $1(5.6)$ & $210[12]$ & 21 [12] & 116 \\
\hline & Oxytetracycline & $5(27.8)$ & 416 [17] & $0.1[13]$ & 65 \\
\hline & Tetracycline & $6(33.3)$ & $231[10]$ & $0.6[17]$ & 41 \\
\hline Thioamides & Ethionamide & $1(5.6)$ & 9.3 [39] & 0.2 [39] & 4.8 \\
\hline
\end{tabular}

* LOQ values were not considered; H, Hospital; ${ }^{* *}$ the effluent WW of this facility undergoes treatment in a municipal biological WWTP, of which data were not available [11]. The second-highest concentration of ofloxacin in effluent WW was 3051 ng/L [12].

The high and ubiquitous presence of these compounds in influents and effluents depends on several factors, mainly related to the consumption and the physicochemical characteristics of the drug. For instance, combinations of trimethoprim and sulfamethoxazole are widely used to treat urinary and respiratory tract infections and are also administered to patients with AIDS or other conditions of immunosuppression [15]. Furthermore, the constant presence of PRs in WW effluents can be attributed to the process of sorption that may occur when PRs accumulate in the sludge of WWTPs. Especially during the final phases of treatment, the substances attached to the sediment particles might be redissolved due to gas bubbling [39], leading to an increase in the detected PR concentration [13]. Moreover, degradation products resulting from the breakdown of PRs or conjugated forms, such as the N4-acetylsulfamethoxazole for the sulfamethoxazole, might transform back into the parent compounds under biological activity that occurs during the activated sludge process $[15,36,39]$.

To conclude, it may be stated that the ubiquitous and constant presence of ciprofloxacin, clarithromycin, erythromycin, sulfamethoxazole, trimethoprim, metronidazole and ofloxacin requires the utmost attention. Indeed, although the first five compounds have already been included in the watch list, specific attention must be given to the other two compounds detected at worrying concentrations. 


\subsection{Seasonal Differences in Concentrations of Pharmaceuticals}

To assess if it is possible to define potential seasonal differences in the PRs levels in sewage water in both influent and effluent, it is crucial to understand what sampling campaigns were carried out in the eighteen studies. However, here too, some criticisms may be levied, as nearly $50 \%$ of the works focused their research of PRs on a period shorter than one week, a time that can only provide a punctiform view of the situation. Conversely, ten studies out of eighteen have investigated a more extended period, and three carried on annual campaigns $[10,35,50]$, although only a few works provided accurate information on the efforts made to assess potential correlation between seasons and levels of antimicrobial substances in WWTPs $[10,17,37,50]$. From the analysis of these latter four studies, it is not realistic to obtain statistical results applicable to a worldwide context, especially considering the extremely high degree of variability in climate conditions across countries; however, the data collected in this study are particularly beneficial in estimating the potential modifiers for seasonal PR concentrations.

What emerged from this scrutiny is the contradictory nature of outcomes, perfectly exemplified by the study of Rodriguez-Mozaz and colleagues on the presence of antibiotic residues in the effluents of 13 European WWTPs [10]. Although the authors of this comprehensive monitoring observed in WW samples from Finland, Ireland and Spain higher concentrations of antibiotics in early spring (March 2015 and 2016) than in early autumn (September 2015 and October 2016), no clear seasonal trend was detected for Germany, Norway or Portugal and an inverse trend was observed in one treatment facility in Cyprus, with higher levels in autumn than in spring. On the other hand, the investigation of AfonsoOlivares et al. on the seasonal variation of 23 pharmaceutical compounds in two WWTPs in Gran Canaria did not exhibit significant variance in their sampling campaigns [37]. In contrast, Kot-Wasik and colleagues showed that the concentrations of 25 PRs detected in the effluent of a Polish treatment facility were higher in winter than in warmer seasons [50]. Finally, as emphasised by Ren et al. [17], the contribution of tourism may lead to an increase in the concentrations and loads of PRs during the high season.

The discrepancies between the studies are accentuated when looking at the seasonal differences for individual pharmaceutical compounds. For example, ciprofloxacin was detected at higher concentrations both in a Norwegian WWTP during autumn and in a Finnish WWTP during spring. The same trend was observed for metronidazole at higher concentrations in Germany and Finland during the cold months and in Spain and Norway during warmer months [10]. Levels of erythromycin during winter and spring in Poland were two-thirds higher than the levels during summer and autumn [50]; conversely, in other countries, macrolides did not show significant seasonal variations [10,37].

Statistical analyses were performed to assess seasonal differences in influent and effluent concentrations among the 14 PRs occurring in more than a quarter of the studies (Supplementary Material Tables). Figure 5 shows the only two significant seasonal differences identified in this study regarding levels of ofloxacin and sulfamethoxazole in influents. The concentration of ofloxacin was significantly higher during autumn than winter ( $p$-value: 0.006$)$, spring ( $p$-value: 0.001 ) or summer ( $p$-value: 0.001$)$. A different trend was observed for sulfamethoxazole, which was significantly higher during winter than in spring ( $p$-value: 0.04$)$.

Seasonal variations were also investigated in the effluents of WWTPs. In this case, significant differences in effluent concentrations across seasons were observed for azithromycin and ciprofloxacin. The azithromycin concentration was significantly higher during winter than in summer ( $p$-value: 0.019). Inversely the pattern observed for ciprofloxacin was higher in spring than winter ( $p$-value: 0.005$)$, summer ( $p$-value: 0.001 ) or autumn ( $p$-value: 0.009$)$ (Figure 6). 


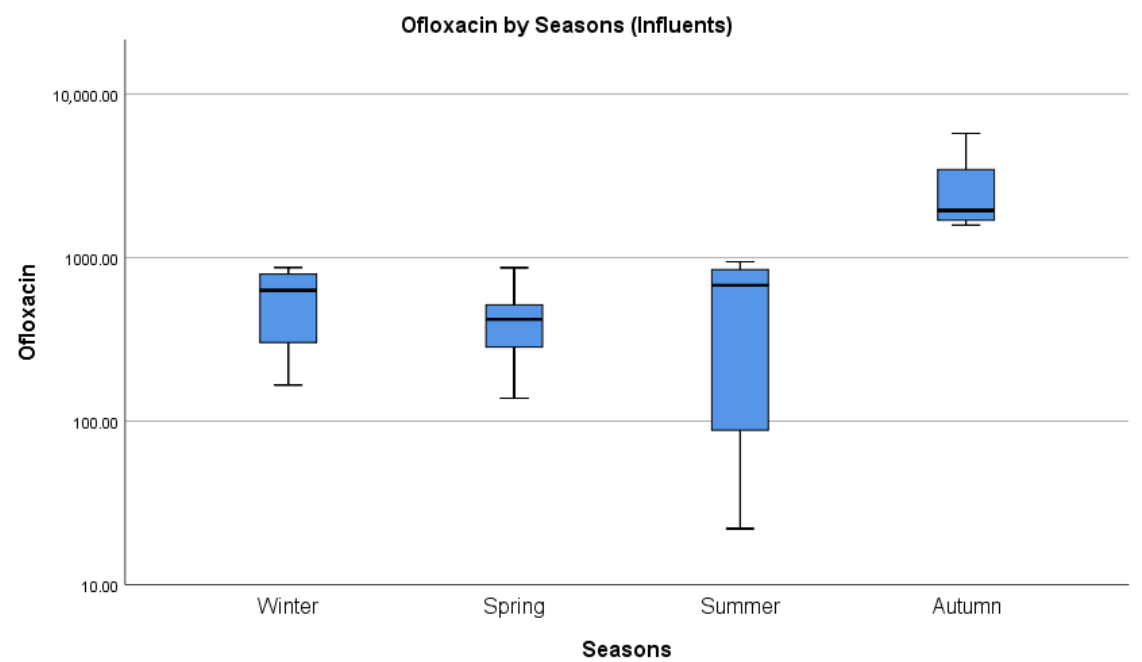

(a)

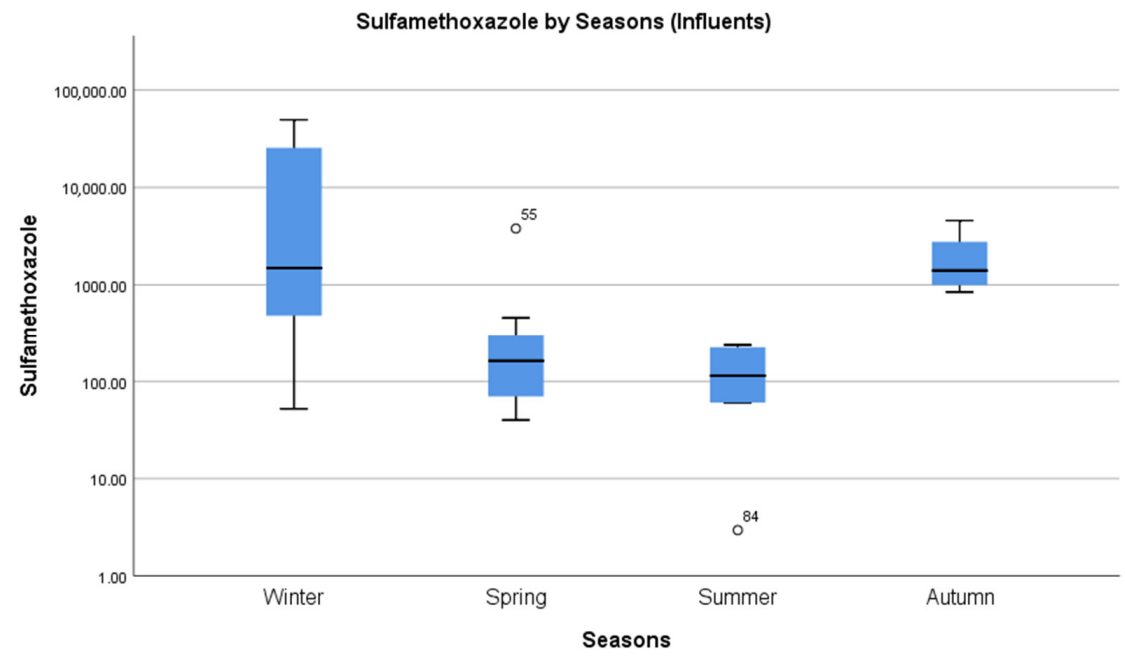

(b)

Figure 5. Seasonal differences in ofloxacin (a) and sulfamethoxazole (b) concentrations in influent WW (values in ng/L are reported on a $\log 10$ scale). Results of one-way ANOVA are illustrated in the Supplementary Material (Tables S4-S7).

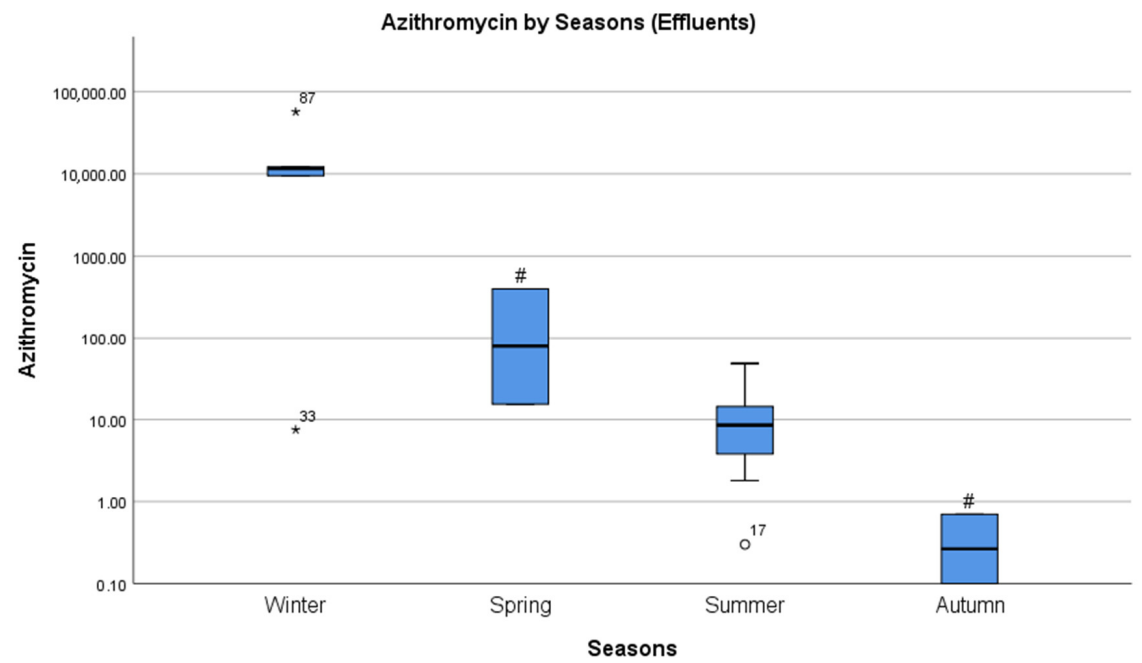

(a)

Figure 6. Cont. 


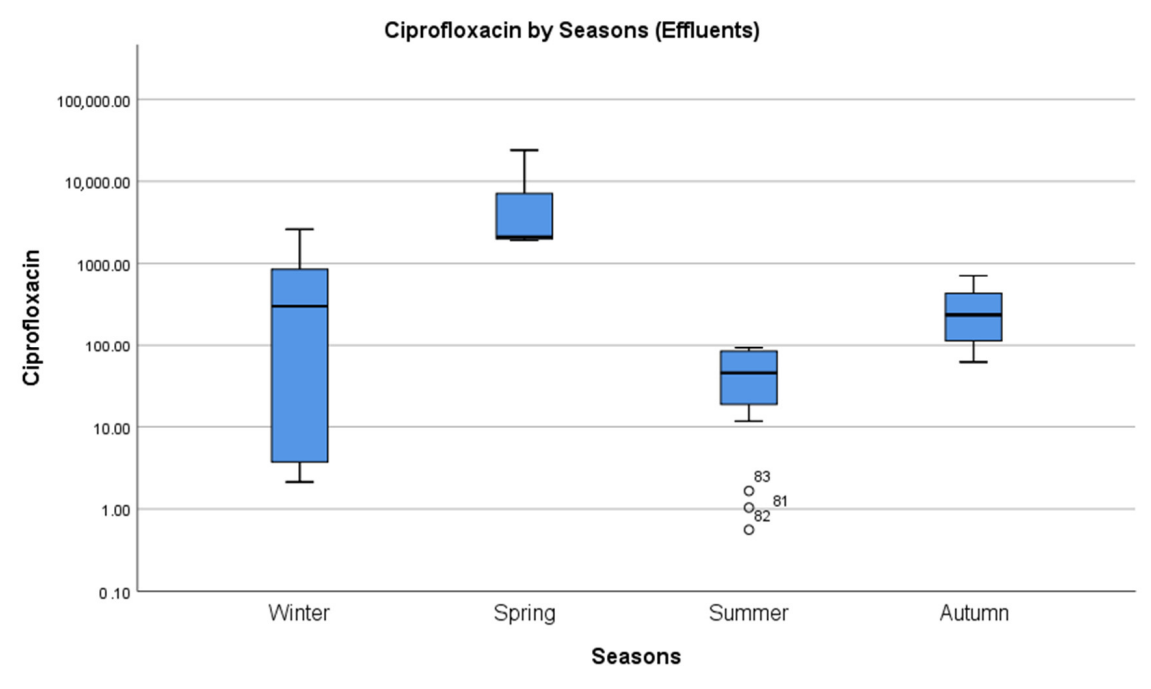

(b)

Figure 6. Seasonal differences in azithromycin (a) and ciprofloxacin (b) concentrations in effluent WW (values in $\mathrm{ng} / \mathrm{L}$ are reported on a $\log 10$ scale). Asterisks indicate that comparisons between means were not performed for azithromycin concentrations in spring and autumn because the two groups had fewer than two cases (WWTPs). Results of one-way ANOVA and the independent $t$-test are illustrated in the Supplementary Material (Tables S8-S11).

Therefore, we can assume that sulfamethoxazole, azithromycin and ciprofloxacin concentrations in WW may be influenced by seasonal factors. Their concentrations were higher during the cold months than warm months, probably due to higher winter and spring consumption or they are more readily broken down at higher temperatures. That does not apply to ofloxacin, which showed higher influent concentrations during the autumn than the other months. That data could be skewed by the high concentrations of ofloxacin reported in Durban by Faleye et al. during their sampling campaign that took place in late summer and autumn [39]. Indeed, the high concentrations of this antibiotic depend on its use in treating pneumonia, the highest non-seasonal killer infection in South Africa [39].

Considering the above, although the higher consumption of antimicrobial substances in autumn and winter due to the more numerous infections occurring in this period [13] should imply a consequent increase in the PRs levels in WW, the contrasting outcomes of the studies did not allow to corroborate this hypothesis. As anticipated in the section on the heterogeneity of the literature, several reasons may influence the concentrations of antimicrobial substances in sewage water, inter alia, habits of consumption of specific class of PRs [37], precipitation [50], temperature [10], the intensity of solar radiation and fluctuating daylight hours between countries studied [50] or the flow rate of the treatment facilities [37]. Moreover, socio-economic and cultural aspects may influence the consumption of certain classes of PRs directly, as proven above [39]. Finally, a clarification is opportune when it comes to evaluating the seasonality of PRs in WW: non-specific approaches attempting to assess worldwide seasonal variations could fail at unveiling differences if they do not take into account modifiers, such as the environmental conditions of the assessed countries. Therefore, it is advisable to increase annual monitoring of influents and effluents of WWTPs to better understand the seasonal relationship between antibiotic consumption and the occurrence of PRs in WW, whilst observing that sub-group analyses on the consumption and release of these compounds in countries with similar climatic conditions should be favoured.

\subsection{Concentrations of Pharmaceuticals in Hospital Wastewater}

Four studies examined influents and effluents WW from 13 hospital wastewater treatment plants (HWWTPs). As could be expected, a high level of heterogeneity was 
found across the samples; 31 PRs of the 45 were detected in influent and effluent hospitals wastewater (HWW). Twenty appeared individually in only one of the four studies. Of the remaining 11 PRs, ciprofloxacin was detected in all the studies in 12 hospitals, ofloxacin, sulfadiazine and sulfamethoxazole were found in three studies in 8,7 and 6 facilities, respectively. Yilmaz et al. found the highest levels of ciprofloxacin $(24,000 \mathrm{ng} / \mathrm{L})$ and sulfamethoxazole $(8500 \mathrm{ng} / \mathrm{L})$ in two samples of WW directly discharged into the Sea of Marmara (Istanbul, Turkey) after a pre-treatment [11]. The authors also detected the highest level of ofloxacin (200,000 ng/L) among the eighteen studies in sewage from a different hospital, but this undergoes treatment in a municipal biological WWTP, for which the data was unavailable [11]. The highest concentration of sulfadiazine ( $373 \mathrm{ng} / \mathrm{L})$ was detected by Li and colleagues in one of the HWWTPs of Xinjiang, China [48]. On the other hand, Paulus et al. reported the lowest values of these four compounds and the lowest concentration of sulfamethoxazole $(1 \mathrm{ng} / \mathrm{L}$, post-treatment) from all of the eighteen studies in hospital sewages treated with an advanced on-site treatment consisting of four steps: microfiltration, ozonation, activated carbon filtration and UV treatment [35].

When statistical analyses were performed to assess potential differences in the concentrations of the most occurring PRs in hospital and municipal WWTPs, sulfadiazine and tetracycline showed the highest levels in HWWTPs influents and effluents. In detail, the mean concentration of sulfadiazine in HWW was higher in both influents ( $p$-value: 0.005 ) and effluents ( $p$-value: 0.000$)$ than the concentration in municipal WWTPs. The same applied for tetracycline levels in the influents of WWTPs, as these were reported to be higher in the hospital treatment facilities ( $p$-value: 0.008) (Figure 7).

The results of this work suggest that hospital sewage water is a hazardous reservoir due to the accumulation of high concentrations of PRs, especially sulfadiazine and tetracycline, as it is widely understood that these high concentrations, when exposed to microbiomes in WWTP, can lead to the development of AMR through the horizontal gene transfer of antimicrobial resistance genes $[35,48]$. Furthermore, given the potential cytotoxic and mutagenic effects of PRs in HWW [11], more emphasis should be given to monitoring HWWTPs influents and effluents and developing innovative PR removal treatment systems.

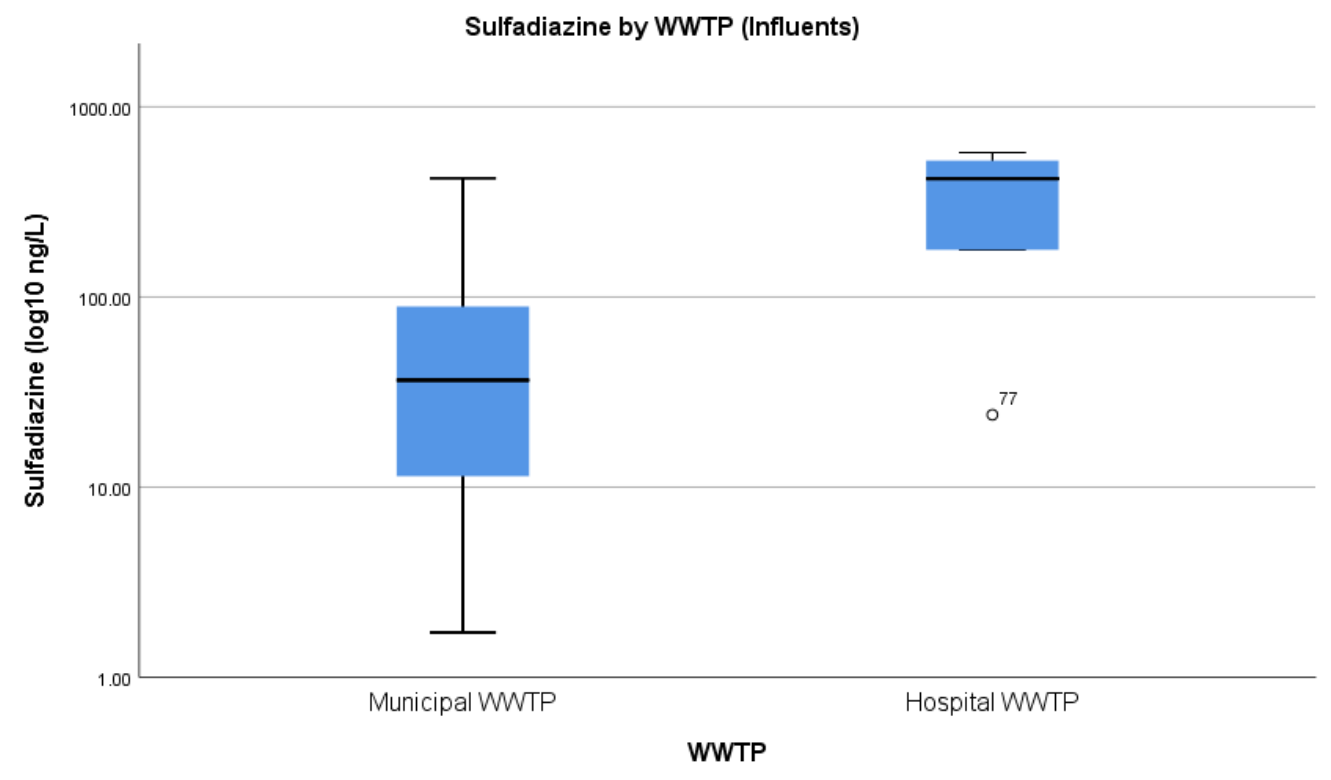

(a)

Figure 7. Cont. 


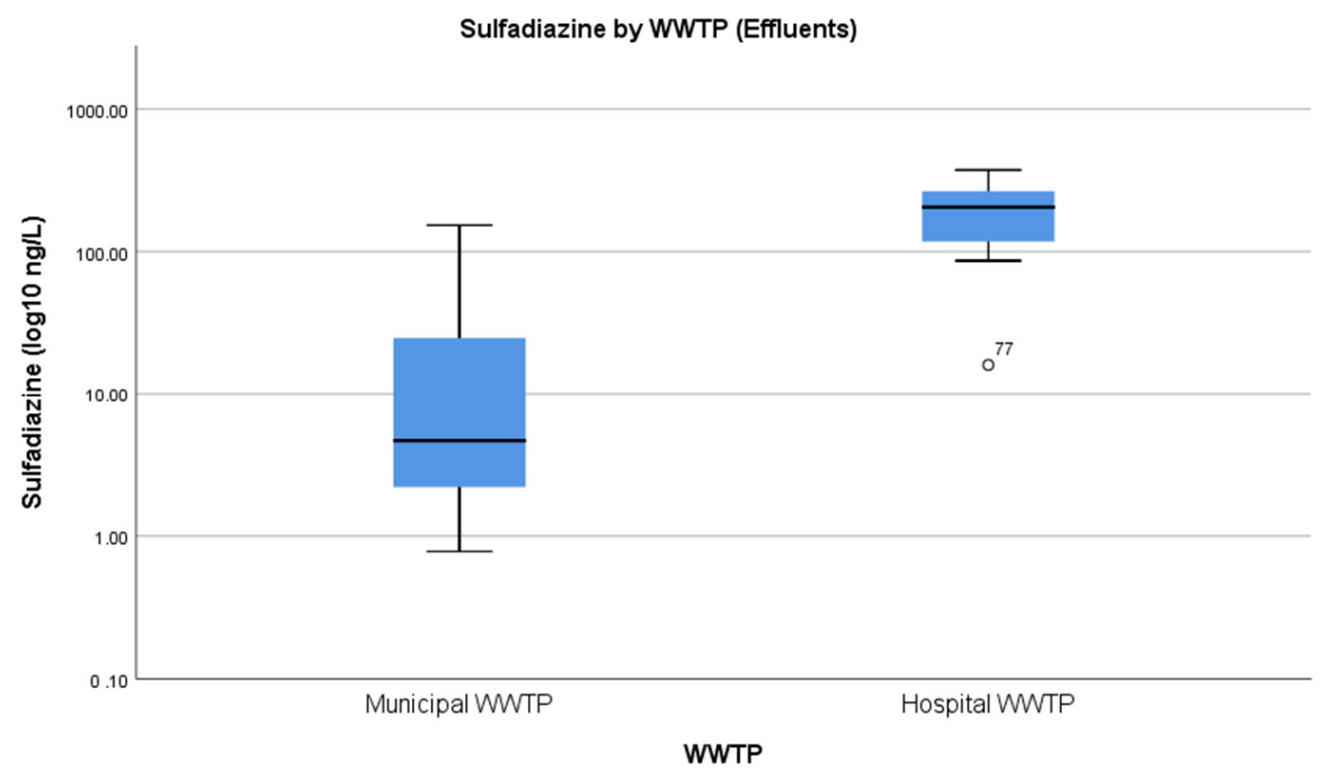

(b)

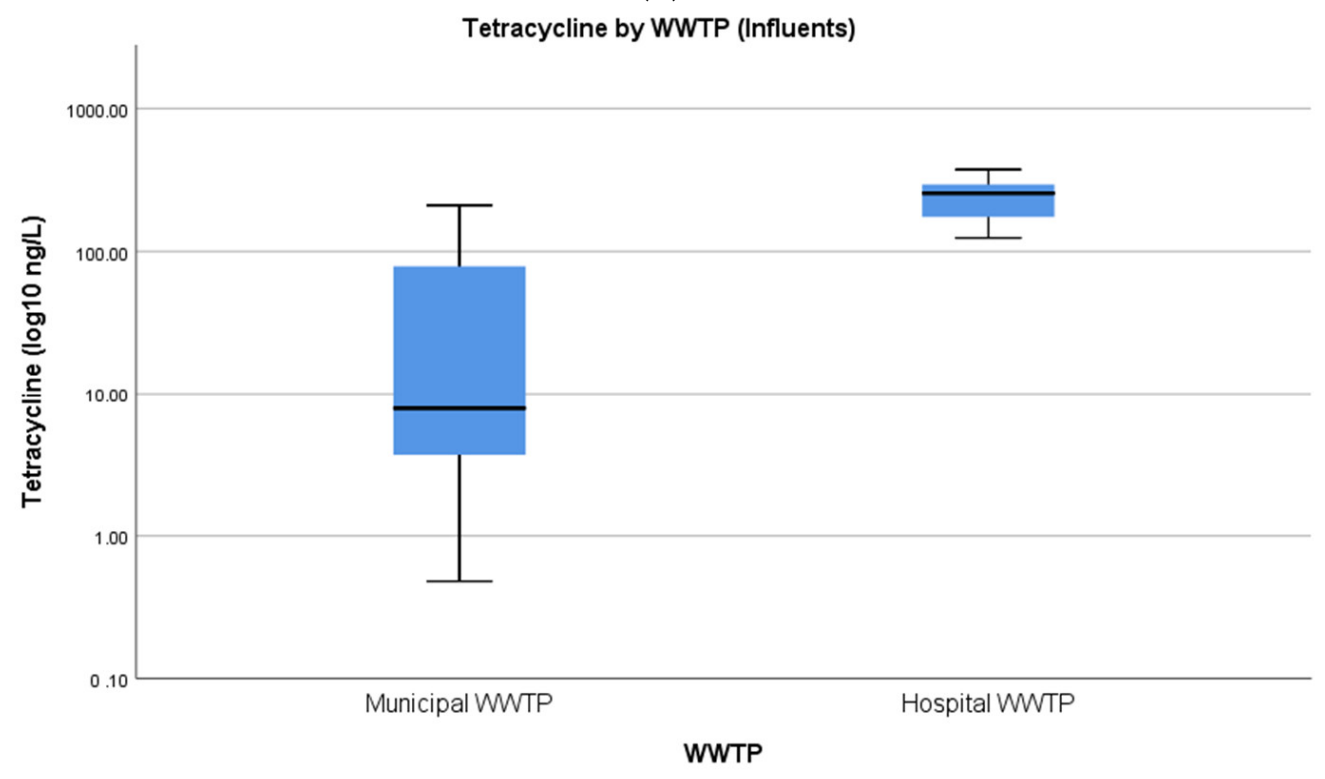

(c)

Figure 7. Differences in sulfadiazine (a,b) and tetracycline (c) concentrations in influent and effluent hospital and municipal WWTPs (values in $\mathrm{ng} / \mathrm{L}$ are reported on a $\log 10$ scale). Results of the independent $t$-tests are illustrated in the Supplementary Material (Tables S12-S18).

\subsection{Environmental Risk Assessment}

Out of eighteen studies, seven assessed the environmental risk using the risk quotient $(R Q)$, reported here as the quotient between MEC (measured environmental concentration) and PNEC (predicted no-effect concentration). The environmental risk assessments considered here evaluated the potential impact of the occurrence of chemical compounds discharged into the environment on the organisms of aquatic ecosystems, such as algae, daphnids and fish. Usually, the RQ results were classified as low, medium and high risk, where $R Q$ with a value $\leq 0.1$ implies a minimum risk to the organisms, the range between 0.1 and 1 indicates medium risk and an $R Q \geq 1$ implies high risk. However, in one study, the high-risk interpretation started from $R Q$ values $\geq 10$ [11]. RQs represented here (Table 6) are the resulting analyses on 20 countries, of which only one is not in Europe; 
therefore, they can provide a faithful representation of the environmental risk posed by

PRs released solely in this area.

Table 6. Environmental risk assessment for PRs that posed a high risk to the environment.

\begin{tabular}{|c|c|c|c|c|}
\hline Pharmaceutical & $\begin{array}{l}\text { No. of Studies in Which the } \\
\text { PRs Exceeded the High-risk } \\
\text { Level (\% of the Total) }\end{array}$ & $\begin{array}{l}\text { Risk Quotient (RQ) }{ }^{a} \text { for PRs in } \\
\text { Effluent WW (Countries) }\end{array}$ & $\begin{array}{l}\text { Highest Detected Average } \\
\text { Conc. in WWTPs } \\
\text { Effluents (ng/L) }\end{array}$ & Refs. \\
\hline Amoxicillin & $1(12.5)$ & 6.4 (Kenya) & 1600 & [15] \\
\hline Azithromycin & $3(37.5)$ & $\begin{array}{l}\text { 0.02-377.8 (China) } \\
\text { 3.6-56.9* (Cyprus, Finland, } \\
\text { Germany, Ireland, Portugal, Spain) } \\
\text { 1.3-34.2 (Poland) }\end{array}$ & $\begin{array}{l}56,666 \\
598 \\
650\end{array}$ & $\begin{array}{l}{[17]} \\
{[10]} \\
{[13]}\end{array}$ \\
\hline Cefalexin & $1(12.5)$ & $\begin{array}{l}1.2-17.0 * \text { (Cyprus, Ireland, } \\
\text { Portugal, Spain, Finland) }\end{array}$ & 308 & [10] \\
\hline Ciprofloxacin & $3(37.5)$ & $\begin{array}{l}40.6 \text { (Kenya) } \\
24.212 \text { a (Spain) } \\
1.6-19.6 \text { * (Cyprus, Finland, } \\
\text { Germany, Ireland, Portugal, Spain) }\end{array}$ & $\begin{array}{l}2600 \\
89 \\
589\end{array}$ & $\begin{array}{l}{[15]} \\
{[37]} \\
{[10]}\end{array}$ \\
\hline Clarithromycin & $3(37.5)$ & $\begin{array}{l}16.7 \text { (Switzerland) } \\
1.9-4.0 \text { (Poland) } \\
1.8-4.6 \text { * (Germany, Ireland, } \\
\text { Portugal, Spain) }\end{array}$ & $\begin{array}{l}234 \\
160 \\
313\end{array}$ & $\begin{array}{l}{[14]} \\
{[13]} \\
{[10]}\end{array}$ \\
\hline Ofloxacin & $2(14.29)$ & $\begin{array}{l}2.6 \text { (Danube river basin) }{ }^{b} \\
0.02-1.3 \text { (China) }\end{array}$ & $\begin{array}{l}3051 \\
180\end{array}$ & $\begin{array}{l}{[12]} \\
{[17]}\end{array}$ \\
\hline Norfloxacin & $1(12.5)$ & 5.8 (Kenya) & 2900 & [15] \\
\hline Roxithromycin & $1(12.5)$ & $0.1-98.2$ (China) & 6272 & [17] \\
\hline Sulfathiazole & $1(12.5)$ & 0-3.2 (China) & 134 & [17] \\
\hline Sulfamethoxazole & $3(37.5)$ & $\begin{array}{l}12.7 \text { (Spain) } \\
3.5 \text { (Kenya) } \\
1.1-1.3 \text { (Poland) }\end{array}$ & $\begin{array}{l}977 \\
21,400 \\
770\end{array}$ & $\begin{array}{l}{[37]} \\
{[15]} \\
{[13]}\end{array}$ \\
\hline Trimethoprim & $1(12.5)$ & 1.0 (Kenya) & 500 & {$[15]$} \\
\hline
\end{tabular}

${ }^{a}$ Values did not account for dilution factors. ${ }^{\mathrm{b}}$ Average of 13 WWTPs in Austria, Croatia, Czech Republic, Germany, Hungary, Romania, Serbia, Slovakia and Slovenia. ${ }^{*}$ Worst-case scenario, according to the authors. PEC (Predicted Environmental Concentration) values multiplied by the dilution factors to obtain MEC values.

Among the 27 antimicrobial substances assessed, azithromycin, ciprofloxacin, clarithromycin, sulfamethoxazole and ofloxacin were reported as the PRs with the highest RQ values. Once again, the need to spotlight the frequency these harmful PRs were detected at high concentrations must be stressed. In certain countries, such as Cyprus, Portugal, Ireland, Spain, Germany, Kenya and China, the presence of more than three PRs exceeding the moderate-risk value is a cause for concern $[10,12,15,17]$. In contrast, in Finland, Switzerland, Norway and Italy, few or no PRs exceeding the highest RQ value were reported $[10,14]$. Moreover, although the high concentrations of ofloxacin, ciprofloxacin and sulfamethoxazole described for the hospitals of Istanbul were worrying, the RQ values relative to the effluent of the biological WWTPs were moderately low, 0.1, 1.7 and 0.2, respectively [11].

Many PRs are discharged into the environment as a mixture; here, the harmful impact of these compounds may be exacerbated by the synergistic effects that naturally occur. Therefore, given that these effects could lead to mutagenic and genotoxic consequences [11,37], the assessment of the risk to the environment is an essential parameter that should always be considered during the monitoring of PRs pollution in water bodies. 


\subsection{Removal Efficiencies of Wastewater Treatment Plants}

The removal performances of 23 municipal WWTPs investigated in six studies were assessed. Removal capacities of WWTPs depend mainly on the typologies of treatments carried out in WWTPs. Besides the precipitation step common for most facilities, in thirteen of them, WW treatment was represented only by standard biological treatment (e.g., activated sludge) $[5,36,37,50]$. On the other hand, eight WWTPs employed oxidation ditches or anaerobic/anoxic/aerobic processes $[5,17]$. In detail, among the six studies, the process of activated sludge was widely shared. In addition to this step, five WWTPs employed biological active filter [39] or membrane bioreactor [5] during the secondary treatments. Regarding tertiary treatment, one of the WWTPs used the highly effective process of reverse osmosis [37], whereas four employed chlorination [39]. Considering the variability of the typologies of treatments across studies, it is inconceivable to produce a consistent and credible comparison between studies; moreover, it goes beyond the scope of this review to report the variation within the single study. Therefore, no correlation between the kind of treatment and the removal performance of the WWTPs was examined.

Seven compounds, namely ciprofloxacin, clarithromycin, erythromycin, metronidazole, ofloxacin, sulfamethoxazole and trimethoprim, were the most representative PRs (Table 7). The average removal efficiencies for each PR varied significantly and were highly influenced by negative removal levels, reported when concentrations in effluents were higher than those in influents. With the exception of ciprofloxacin, which seemed efficiently removed by all the WWTPs in which it was detected, all the PRs exhibited an erratic removal pattern. In detail, sulfamethoxazole, erythromycin and metronidazole demonstrated the most resistance to degradation. Although low removal performances for the latter two compounds were previously described $[5,36,39,50]$, the negative values reported by Afonso-Olivares et al. in two WWTPs in Gran Canaria (Spain) [37] strongly influenced the average reduction for sulfamethoxazole. Negative values were also detected for trimethoprim; Ren and colleagues registered $-23 \%$ removal of this antibiotic in a treatment facility in Sanya City [17]. Contrastingly, Moslah et al. reported a complete removal of ciprofloxacin and clarithromycin in seven Tunisian WWTPs [36].

Table 7. Removal efficiencies of the PRs most commonly found in WW.

\begin{tabular}{lllll}
\hline Pharmaceutical & $\begin{array}{l}\text { No. of Studies in Which the } \\
\text { PRs Occur (\% of the Total) }\end{array}$ & $\begin{array}{l}\text { Max Removal } \\
\text { Efficiency (\%) }\end{array}$ & $\begin{array}{l}\text { Min Removal } \\
\text { Efficiency (\%) }\end{array}$ & $\begin{array}{l}\text { Average Removal Efficiency } \\
\text { among }\end{array}$ \\
\hline Erythromycin & $5(83.3)$ & $99.9[37]$ & $-193.0[39]$ & 10.3 \\
Sulfamethoxazole & $5(83.3)$ & $100.0[39]$ & $-504.2[37]$ & 22.2 \\
Metronidazole & $3(50.0)$ & $99.9[37]$ & $-320.0[5]$ & 28.5 \\
Trimethoprim & $5(83.3)$ & $99.9[37]$ & $-23.0[17]$ & 54.0 \\
Clarithromycin & $4(66.7)$ & $100.0[36,39]$ & $-22.0[5]$ & 68.1 \\
Ofloxacin & $5(83.3)$ & $100.0[39]$ & $7.0[36]$ & 79.9 \\
Ciprofloxacin & $4(66.7)$ & $100.0[36,39]$ & $44.5[17]$ & 88.4 \\
\hline
\end{tabular}

These unpredictable outcomes are the result of the treatment facility characteristics, some of which were mentioned above. However, conclusions about the efficacy of the treatment should be drawn with caution, considering that the absence of antimicrobial substances in the effluent does not always correspond to high efficiencies of removal. In particular, Faleye et al. correlated percentages of reduction for fluoroquinolones higher than $90 \%$ to the chemical properties of these compounds being absorbed by treatment sludge [39]. The chemical properties of PRs are relative to the success of the sorption process and in the PR removal performances of WWTPs, and these further explain most of the negative percentage removal values. For instance, N4-acetylsulfamethoxazole, the conjugate form of sulfamethoxazole, might transform back into the parent compound, leading to an increase in the concentration of sulfamethoxazole in the effluents [15,36,39]. Moreover, Afonso-Olivares and colleagues reported negative removal efficiencies of this compound potentially due to water flow variations and evapotranspiration [37]. 
Given the above, the need to evaluate the occurrence of antimicrobial substances in both effluents and sludge is required to better comprehend the process of sorption and to accurately assess the removal performances of WWTPs.

\subsection{Classification of the Pharmaceuticals of Greatest Concern}

Out of the 45 antimicrobial substances detected amongst the target studies, ciprofloxacin, clarithromycin, erythromycin, metronidazole, ofloxacin, sulfamethoxazole and trimethoprim constitute a considerable risk in terms of ubiquitous distribution. In particular, sulfamethoxazole frequently appeared in the studies as the compound with the most worrying high concentrations, $R Q$ values and capacities to resist removal treatments. However, in order to establish a classification of the most concerning antimicrobial substances relevant to the question of this review, it is crucial to consider the potentialities of the PRs to induce AMR. To accomplish this, a classification of the seven compounds, based on the limits for environmental regulation proposed by Bengtsson-Palme and Larsson [51], was designed (Table 8). Two parameters were considered to establish the list: the minimal inhibitory concentrations (MIC) and the predicted no-effect concentrations (PNEC). Briefly, the reported MICs, adjusted for the number of tested species, correspond to the estimated upper boundaries for the minimal selective concentration (MSC) [51], which indicates the lowest pharmaceutical concentration that gives a competitive advantage to resistant bacterial strains during growth [52]. PNECs, representing the size-adjusted lowest MICs divided by an assessment factor of 10, were used to produce the list in which the PRs were sorted according to the number of times the antimicrobial substance exceeded the PNEC values for resistance selection.

Table 8. Classification of the pharmaceuticals of greatest concern sorted according to the percentage of studies in which the reported concentrations in effluents exceeded the PNECs for resistance selection (adapted from Bengtsson-Palme and Larsson, 2016).

\begin{tabular}{|c|c|c|c|c|c|}
\hline \multicolumn{4}{|c|}{ Bengtsson-Palme and Larsson Study } & \multicolumn{2}{|c|}{ This Study } \\
\hline Pharmaceutical & $\begin{array}{l}\text { No. of Different } \\
\text { Species with } \\
\text { Reported MIC }\end{array}$ & $\begin{array}{l}\text { Size-Adjusted } \\
\text { Lowest MIC a } \\
\text { (ng/L) }\end{array}$ & $\begin{array}{l}\text { PNEC }^{b} \\
\text { Resistance } \\
\text { Selection (ng/L) }\end{array}$ & $\begin{array}{l}\%>\text { MIC }^{c} \\
\text { (No. of Studies) } \\
\text { [ref.] }\end{array}$ & $\begin{array}{l}\%>\text { PNEC }^{\mathrm{d}} \\
\text { (No. of Studies) }\end{array}$ \\
\hline Ciprofloxacin & 70 & 1000 & 64 & $16.67(2),[2,16]$ & $75.0(9)$ \\
\hline Clarithromycin & 15 & 2000 & 250 & $9.09(1),[11]$ & $45.5(5)$ \\
\hline Ofloxacin & 26 & 4000 & 500 & $9.09(1),[11]$ * & $45.5(5)$ \\
\hline Trimethoprim & 22 & 8000 & 500 & $7.69(1),[6]$ & $30.8(4)$ \\
\hline Metronidazole & 6 & 2000 & 125 & $12.50(1),[11]$ & $25.0(2)$ \\
\hline Erythromycin & 39 & 8000 & 1000 & $0.00(0)$ & $22.2(2)$ \\
\hline Sulfamethoxazole & 8 & 125,000 & 16,000 & $0.00(0)$ & $6.7(1)$ \\
\hline
\end{tabular}

${ }^{a}$ Size-adjusted lowest MIC prediction, corresponding to the estimated upper boundary for the MSC. ${ }^{b}$ PNEC resistance selection referred to the size-adjusted lowest MIC divided by an assessment factor of $10 .{ }^{c}$ Percentage of studies in which the pharmaceutical reported concentrations exceeded the size-adjusted lowest MIC (number of studies). ${ }^{d}$ Percentage of studies in which the pharmaceutical reported concentrations exceeded the PNEC resistance selection (number of studies). * Hospital.

Looking at the classification, ciprofloxacin, clarithromycin and ofloxacin are the most worrying antimicrobial substances that may lead to AMR. Indeed, out of twelve studies in which ciprofloxacin was detected (at levels higher than limits of quantification), in nine of them, concentrations exceeded the PNEC for resistance selection. Conversely, only one study out of fifteen reported a sulfamethoxazole concentration above the PNEC [15]. However, as Bengtsson-Palme and Larsson stressed, PRs tested against a minimal number of bacterial species showed higher PNEC values, suggesting that the representativity of the bacterial sensitivity could be compromised by a limited number of tested species (2016). On the other hand, concentrations of the seven of concern PRs exceeded the MIC values in only three of the studies observed. Finally, it is fair to point out that the values here reported did not account for the dilution that naturally occurs after the discharge of treated 
WW in the aquatic environment. Indeed, once released in rivers, lakes or seas, the PRs may be diluted, potentially reducing the likelihood of the development of AMR.

\section{Conclusions and Recommendations}

The present study aimed to appraise all relevant literature for the presence of pharmaceuticals responsible for the development of antimicrobial resistance in wastewater and to provide detailed and updated information valuable for the management of AMR dissemination in wastewater treatment plants.

The review of 18 studies covered 25 countries; 21 are European. Therefore, it can be asserted that notwithstanding that the discharge of harmful antimicrobials is a widespread global issue, research is of particular significance to Europe.

Here, a list of the seven most concerning pharmaceuticals commonly found in the influents and effluents of wastewater treatment plants is proposed. Ciprofloxacin, clarithromycin, erythromycin, metronidazole, ofloxacin, sulfamethoxazole and trimethoprim constitute a considerable risk in terms of ubiquitous distribution, worrying concentrations and $R Q$ values and capacities to resist removal treatments. Especially concerning were the PRs ciprofloxacin, clarithromycin and ofloxacin as these were frequently detected at levels above the predicted no-effect concentrations for resistance selection, which make these compounds the most concerning antimicrobials that encourage the development of antimicrobial resistance.

In conclusion, based on the gaps in knowledge identified during this systematic review, the main recommendations are as follows:

- The reliability of study outcomes must be improved through the implementation of standardised guidelines for the suitable selection of analytical procedures, data representation, and statistical analysis. The experiments should not be based on daily campaigns composing of a singular grab sample, but instead, values for concentrations should be the result of the mean of at least three replicates.

- The need remains for time-weighted screenings to capture seasonal variations in both the influent levels of pharmaceuticals and the effluent levels discharged into aquatic matrices to better assess the impact of wastewater treatment plants on the environment.

- The necessity of studies dealing specifically with the presence of antimicrobial substances in hospital wastewater or correlating the removal efficiencies of wastewater treatment plants with treatments used is stressed.

- Call for awareness about the problem of pharmaceuticals compounds in wastewater and the related spread of antimicrobial resistance: the research in this field needs to be expanded to a global level.

Supplementary Materials: The following are available online at https://www.mdpi.com/article/10 .3390/app11156670/s1. Tables.docx: Table S1: Pre-set list of exclusion and inclusion criteria for the title and abstract screening phases. Table S2: Pre-set list of characteristics and results that were coded and extracted from each study. Table S3: Strings designed for each database. Tables S4-S7: One-way ANOVA results on the seasonal differences in ofloxacin and sulfamethoxazole concentrations in influent WW. Tables S8-S11: One-way ANOVA and independent $t$-test results on the seasonal differences in azithromycin and ciprofloxacin concentrations in effluent. Tables S12-S18: Independent $t$-test results on the seasonal differences in sulfadiazine and tetracycline concentrations in influent and effluent hospital and municipal WWTPs. Data_extraction.xlsx: Risk of bias, Influents, Effluents, Removals, Risk Assessment and PRs list. References [53-59] refer to the supplementary material.

Author Contributions: Conceptualisation, G.F.; methodology, G.F.; software, G.F.; validation, G.F., D.R., J.R., C.H., A.E. and K.H.; formal analysis, G.F.; investigation, G.F. and D.R.; resources, G.F.; data curation, G.F. and D.R.; writing —original draft preparation, G.F. and D.R.; writing-review and editing, J.R., C.H., A.E. and K.H.; visualisation, G.F.; supervision, J.R., J.S., C.H. and A.E.; project administration, G.F.; funding acquisition, C.H., J.R., J.S. and A.E. All authors have read and agreed to the published version of the manuscript.

Funding: The APC was funded by Medical Research Scotland, grant number PHD-50035-2019. 
Institutional Review Board Statement: Not applicable.

Informed Consent Statement: Not applicable.

Data Availability Statement: The data presented in this study are available on request from the corresponding author.

Acknowledgments: A brief word of thanks to Fra Brigasca for the illuminating support throughout all stages.

Conflicts of Interest: The authors declare no conflict of interest. The funders had no role in the design of the study; in the collection, analyses, or interpretation of data; in the writing of the manuscript, or in the decision to publish the results.

$\begin{array}{ll}\text { Abbreviations } & \\ \text { Antimicrobial resistance } & \text { AMR } \\ \text { European Centre for Disease Prevention and Control } & \text { ECDC } \\ \text { High-performance liquid chromatography } & \text { HPLC } \\ \text { Hospital wastewater treatment plants } & \text { HWWTPs } \\ \text { Hospitals wastewater } & \text { HWW } \\ \text { Limit of detection } & \text { LOD } \\ \text { Limit of quantification } & \text { LOQ } \\ \text { Measured environmental concentration } & \text { MEC } \\ \text { Method detection limit } & \text { MDL } \\ \text { Method quantification limit } & \text { MQL } \\ \text { Minimal inhibitory concentrations } & \text { MIC } \\ \text { Minimal selective concentration } & \text { MSC } \\ \text { Organisation for Economic Co-operation and Development } & \text { OECD } \\ \text { Pharmaceutical residues } & \text { PRs } \\ \text { Predicted environmental concentration } & \text { PEC } \\ \text { Predicted no-effect concentration } & \text { PNEC } \\ \text { Risk quotient } & \text { RQ } \\ \text { Solid-phase extraction } & \text { SPE } \\ \text { Ultra-performance liquid chromatography } & \text { UPLC } \\ \text { Wastewater treatment plants } & \text { WWTPs } \\ \text { Wastewater } & \text { WW }\end{array}$

\section{References}

1. Radjenović, J.; Petrović, M.; Barceló, D. Fate and distribution of pharmaceuticals in wastewater and sewage sludge of the conventional activated sludge (CAS) and advanced membrane bioreactor (MBR) treatment. Water Res. 2009, 43, 831-841. [CrossRef]

2. Gros, M.; Petrović, M.; Ginebreda, A.; Barceló, D. Removal of pharmaceuticals during wastewater treatment and environmental risk assessment using hazard indexes. Environ. Int. 2010, 36, 15-26. [CrossRef] [PubMed]

3. Roberts, P.H.; Thomas, K.V. The occurrence of selected pharmaceuticals in wastewater effluent and surface waters of the lower Tyne catchment. Sci. Total Environ. 2006, 356, 143-153. [CrossRef]

4. Li, J.; Baig, S.A.; Chen, H.; Cheng, W.; Jiao, Y.; Xu, L. Occurrence and removal of antibiotics and the corresponding resistance genes in wastewater treatment plants: Effluents' influence to downstream water environment. Environ. Sci. Pollut. Res. 2016, 23, 6826-6835. [CrossRef] [PubMed]

5. Qi, W.; Singer, H.; Berg, M.; Mueller, B.; Pernet-Coudrier, B.; Liu, H.; Qu, J. Elimination of polar micropollutants and anthropogenic markers by wastewater treatment in Beijing, China. Chemosphere 2015, 119, 1054-1061. [CrossRef]

6. Dalahmeh, S.; BjöRnberg, E.; Elenström, A.; Komakech, A.J.; Niwagaba, C.B. Pharmaceutical pollution of water resources in Nakivubo wetlands and Lake Victoria, Kampala, Uganda. Sci. Total Environ. 2020, 710, 136347. [CrossRef] [PubMed]

7. Jaén-Gil, A.; Hom-Diaz, A.; Llorca, M.; Vicent, T.; Blánquez, P.; Barceló, D.; Rodríguez-Mozaz, S. An automated online turbulent flow liquid-chromatography technology coupled to a high resolution mass spectrometer LTQ-Orbitrap for suspect screening of antibiotic transformation products during microalgae wastewater treatment. J. Chromatogr. A 2018, 1568, 57-68. [CrossRef] [PubMed]

8. Jones, H.O.A.; Voulvoulis, N.; Lester, J.N. Human pharmaceuticals in wastewater treatment processes. Crit. Rev. Environ. Sci. Technol. 2005, 35, 401-427. [CrossRef] 
9. Wang, Y.; Lu, J.; Engelstädter, J.; Zhang, S.; Ding, P.; Mao, L.; Yuan, Z.; Bond, P.L.; Guo, J. Non-antibiotic pharmaceuticals enhance the transmission of exogenous antibiotic resistance genes through bacterial transformation. ISME J. 2020, 14, 2179-2196. [CrossRef]

10. Rodriguez-Mozaz, S.; Vaz-Moreira, I.; Varela Della Giustina, S.; Llorca, M.; Barceló, D.; Schubert, S.; Berendonk, T.U.; MichaelKordatou, I.; Fatta-Kassinos, D.; Martinez, J.L.; et al. Antibiotic residues in final effluents of European wastewater treatment plants and their impact on the aquatic environment. Environ. Int. 2020, 140, 105733. [CrossRef]

11. Yilmaz, G.; Kaya, Y.; Vergili, I.; Beril Gönder, Z.; Özhan, G.; Ozbek Celik, B.; Altinkum, S.M.; Bagdatli, Y.; Boergers, A.; Tuerk, J. Characterisation and toxicity of hospital wastewaters in Turkey. Environ. Monit. Assess. 2017, 189, 55. [CrossRef]

12. Alygizakis, N.A.; Besselink, H.; Paulus, G.K.; Oswald, P.; Hornstra, L.M.; Oswaldova, M.; Medema, G.; Thomaidis, N.S.; Behnisch, P.A.; Slobodnik, J. Characterisation of wastewater effluents in the Danube River Basin with chemical screening, in vitro bioassays and antibiotic resistant genes analysis. Environ. Int. 2019, 127, 420-429. [CrossRef]

13. Giebułtowicz, J.; Nałęcz-Jawecki, G.; Harnisz, M.; Kucharski, D.; Korzeniewska, E.; Płaza, G. Environmental Risk and Risk of Resistance Selection Due to Antimicrobials' Occurrence in Two Polish Wastewater Treatment Plants and Receiving Surface Water. Molecules 2020, 25, 1470. [CrossRef]

14. Castiglioni, S.; Zuccato, E.; Fattore, E.; Riva, F.; Terzaghi, E.; Koenig, R.; Principi, P.; Di Guardo, A. Micropollutants in Lake Como water in the context of circular economy: A snapshot of water cycle contamination in a changing pollution scenario. J. Hazard. Mater. 2020, 384, 141441. [CrossRef] [PubMed]

15. Kairigo, P.; Gachanja, A.; Ngumba, E.; Sundberg, L.; Tuhkanen, T. Occurrence of antibiotics and risk of antibiotic resistance evolution in selected Kenyan wastewaters, surface waters and sediments. Sci. Total Environ. 2020, 720, 137580. [CrossRef] [PubMed]

16. Kimosop, S.J.; Getenga, Z.M.; Orata, F.; Okello, V.A.; Cheruiyot, J.K. Residue levels and discharge loads of antibiotics in wastewater treatment plants (WWTPs), hospital lagoons, and rivers within Lake Victoria Basin, Kenya. Environ. Monit. Assess. 2016, 188, 532. [CrossRef] [PubMed]

17. Ren, B.; Geng, J.; Wang, Y.; Wang, P. Emission and ecological risk of pharmaceuticals and personal care products affected by tourism in Sanya City, China. Environ. Geochem. Health 2021. [CrossRef]

18. WHO. The 2019 WHO AWaRe Classification of Antibiotics for Evaluation and Monitoring of Use; World Health Organization: Geneva, Switzerland, 2019. Available online: https://www.who.int/medicines/news/2019/WHO_releases2019AWaRe_classification_ antibiotics/en/ (accessed on 1 November 2020).

19. CDC. Antibiotic Resistance Threats in the United States; US Department of Health and Human Services, CDC: Atlanta, GA, USA, 2019. Available online: https://www.cdc.gov/drugresistance/pdf/threats-report/2019-ar-threats-report-508.pdf (accessed on 1 November 2020).

20. CDC. Antifungal Resistance. Atalanta: Centers for Disease Control and Prevention, 2020. Available online: https://www.cdc. gov / fungal/antifungal-resistance.html\#what-causes (accessed on 1 November 2020).

21. NHS. Antifungal Medicines; National Health System: London, UK, 2020. Available online: https://www.nhs.uk/conditions/ antifungal-medicines / (accessed on 1 November 2020).

22. Yadav, S.; Jadeja, N.B.; Dafale, N.D.; Purohit, H.; Kapley, A. 17-Pharmaceuticals and personal care products mediated antimicrobial resistance: Future challenges. In Pharmaceuticals and Personal Care Products: Waste Management and Treatment Technology; Prasad, M.N.V., Vithanage, M., Kapley, A., Eds.; Butterworth-Heinemann: Oxford, UK, 2019; pp. 409-428.

23. Brown, E.D.; Wright, G.D. Antibacterial drug discovery in the resistance era. Nature 2016, 529, 336-343. [CrossRef] [PubMed]

24. OECD. EU Health Ministerial Meeting-Next Steps towards Making the EU a Best Practice Region in Combating AMR. Bucharest, Romania. 2019. Available online: https:/ / www.oecd.org/health/health-systems/AMR-Tackling-the-Burden-in-the-EU-OECDECDC-Briefing-Note-2019.pdf (accessed on 1 November 2020).

25. Directive 2008/105/EC of the European Parliament and of the Council. Available online: https:/ / eur-lex.europa.eu/eli/dir/20 08/105/oj (accessed on 1 November 2020).

26. Carvalho, R.; Ceriani, L.; Ippolito, A.; Lettieri, T. Development of the First Watch List under the Environmental Quality Standards Directive, 2015. Report EUR 27142. Available online: https://publications.jrc.ec.europa.eu/repository/bitstream/JRC95018 /lbna27142enn.pdf (accessed on 1 November 2020).

27. Leimu, R.; Koricheva, J. What determines the citation frequency of ecological papers? Trends Ecol. Evol. 2005, 20, 28-32. [CrossRef]

28. Bayliss, H.R.; Beyer, F.R. Information retrieval for ecological syntheses. Res. Synth. Methods 2015, 6, 136-148. [CrossRef]

29. Song, F.; Parekh, S.; Hooper, L.; Loke, Y.K.; Ryder, J.; Sutton, A.J.; Hing, C.; Kwok, C.S.; Pang, C.; Harvey, I. Dissemination and publication of research findings: An updated review of related biases. Health Technol. Assess. 2010, 14, 1-220. [CrossRef] [PubMed]

30. Dickersin, K. Publication Bias: Recognising the Problem, Understanding Its Origins and Scope, and Preventing Harm. Chapter 2. In Publication Bias in Meta-Analysis: Prevention, Assessment and Adjustments; Rothstein, H.R., Sutton, A.J., Borenstein, M., Eds.; Wiley: Hoboken, NJ, USA, 2006; pp. 9-33.

31. Ebrahimi, S.M.; Dehghanzadeh Reyhani, R.; Asghari-Jafarabadi, M.; Fathifar, Z. Diversity of antibiotics in hospital and municipal wastewaters and receiving water bodies and removal efficiency by treatment processes: A systematic review protocol. Environ. Evid. 2020, 9, 1-9. [CrossRef] 
32. Page, M.J.; McKenzie, J.E.; Bossuyt, P.M.; Boutron, I.; Hoffmann, T.C.; Mulrow, C.D.; Shamseer, L.; Tetzlaff, J.M.; Akl, E.A.; Brennan, S.E.; et al. The PRISMA 2020 statement: An updated guideline for reporting systematic reviews. BMJ $2020,372$. [CrossRef]

33. Higgins, J.P.T.; Altman, D.G.; Gøtzsche, P.C.; Jüni, P.; Moher, D.; Oxman, A.D.; Savović, J.; Schulz, K.F.; Weeks, L.; Sterne, J.A.C. The Cochrane Collaboration's tool for assessing risk of bias in randomised trials. BMJ 2011, 343, d5928. [CrossRef]

34. Li, L.; Guo, C.; Fan, S.; Lv, J.; Zhang, Y.; Xu, Y.; Xu, J. Dynamic transport of antibiotics and antibiotic resistance genes under different treatment processes in a typical pharmaceutical wastewater treatment plant. Environ. Sci. Pollut. Res. 2018, 25, 30191-30198. [CrossRef]

35. Paulus, G.K.; Hornstra, L.M.; Alygizakis, N.; Slobodnik, J.; Thomaidis, N.; Medema, G. The impact of on-site hospital wastewater treatment on the downstream communal wastewater system in terms of antibiotics and antibiotic resistance genes. Int. J. Hyg. Environ. Health 2019, 222, 635-644. [CrossRef] [PubMed]

36. Moslah, B.; Hapeshi, E.; Jrad, A.; Fatta-Kassinos, D.; Hedhili, A. Pharmaceuticals and illicit drugs in wastewater samples in north-eastern Tunisia. Environ. Sci. Pollut. Res. 2018, 25, 18226-18241. [CrossRef] [PubMed]

37. Afonso-Olivares, C.; Sosa-Ferrera, Z.; Santana-Rodriguez, J.J. Occurrence and environmental impact of pharmaceutical residues from conventional and natural wastewater treatment plants in Gran Canaria (Spain). Sci. Total Environ. 2017, 599, 934-943. [CrossRef]

38. Verlicchi, P.; Al Aukidy, M.; Zambello, E. Occurrence of pharmaceutical compounds in urban wastewater: Removal, mass load and environmental risk after a secondary treatment-A review. Sci. Total Environ. 2012, 429, 123-155. [CrossRef]

39. Faleye, A.C.; Adegoke, A.A.; Ramluckan, K.; Fick, J.; Bux, F.; Stenström, T.A. Concentration and reduction of antibiotic residues in selected wastewater treatment plants and receiving waterbodies in Durban, South Africa. Sci. Total Environ. 2019, 678, 10-20. [CrossRef]

40. Singh, R.R.; Angeles, L.F.; Butryn, D.M.; Metch, J.W.; Garner, E.; Vikesland, P.J.; Aga, D.S. Towards a harmonised method for the global reconnaissance of multi-class antimicrobials and other pharmaceuticals in wastewater and receiving surface waters. Environ. Int. 2019, 124, 361-369. [CrossRef]

41. Barancheshme, F.; Munir, M. Strategies to combat antibiotic resistance in the wastewater treatment plants. Front. Microbiol. 2018, 8, 2603. [CrossRef]

42. Scott, G.; Porter, D.; Norman, R.; Scott, C.; Uyaguari-Diaz, M.; Maruya, K.; Weisberg, S.; Fulton, M.; Wirth, E.; Moore, J.; et al. Antibiotics as CECs: An Overview of the Hazards Posed by Antibiotics and Antibiotic Resistance. Front. Mar. Sci. 2016, 3, 24. [CrossRef]

43. Wallace, J.; Youngblood, J.; Port, J.; Cullen, A.; Smith, M.; Workman, T.; Faustman, E. Variability in metagenomic samples from the Puget Sound: Relationship to temporal and anthropogenic impacts. PLoS ONE 2018, 13, e0192412. [CrossRef]

44. Oh, M.; Pruden, A.; Chen, C.; Heath, L.; Xia, K.; Zhang, L. MetaCompare: A computational pipeline for prioritising environmental resistome risk. FEMS Microbiol. Ecol. 2018, 94, fiy079. [CrossRef] [PubMed]

45. Paiva, M.C.; Reis, M.P.; Costa, P.S.; Dias, M.F.; Bleicher, L.; Scholte, L.L.S.; Nardi, R.M.D.; Nascimento, A. Identification of new bacteria harboring qnrS and aac $\left(6^{\prime}\right)-\mathrm{Ib} / \mathrm{cr}$ and mutations possibly involved in fluoroquinolone resistance in raw sewage and activated sludge samples from a full-scale WWTP. Water Res. 2017, 110, 27-37. [CrossRef] [PubMed]

46. Conte, D.; Palmeiro, J.K.; Nogueira, K.D.S.; Lima, R.; Marenda, T.; Cardoso, M.A.; Pontarolo, R.; Degaut Pontes, F.L.; Dalla-Costa, L.M. Characterisation of CTX-M enzymes, quinolone resistance determinants, and antimicrobial residues from hospital sewage, wastewater treatment plant, and river water. Ecotoxicol. Environ. Saf. 2017, 136, 62-69. [CrossRef] [PubMed]

47. Santoro, D.O.; Cardoso, A.M.; Coutinho, F.H.; Pinto, L.H.; Vieira, R.P.; Albano, R.M.; Clementino, M.M. Diversity and antibiotic resistance profiles of Pseudomonads from a hospital wastewater treatment plant. J. Appl. Microbiol. 2015, 119, 1527-1540. [CrossRef]

48. Li, C.; Lu, J.; Liu, J.; Zhang, G.; Tong, Y.; Ma, N. Exploring the correlations between antibiotics and antibiotic resistance genes in the wastewater treatment plants of hospitals in Xinjiang, China. Environ. Sci. Pollut. Res. 2016, 23, 15111-15121. [CrossRef]

49. Huang, H.; Zeng, S.; Dong, X.; Li, D.; Zhang, Y.; He, M.; Du, P. Diverse and abundant antibiotics and antibiotic resistance genes in an urban water system. J. Environ. Manag. 2019, 231, 494-503. [CrossRef]

50. Kot-Wasik, A.; Jakimska, A.; Śliwka-Kaszyńska, M. Occurrence and seasonal variations of 25 pharmaceutical residues in wastewater and drinking water treatment plants. Environ. Monit. Assess. 2016, 188, 661. [CrossRef]

51. Bengtsson-Palme, J.; Larsson, D.G.J. Concentrations of antibiotics predicted to select for resistant bacteria: Proposed limits for environmental regulation. Environ. Int. 2016, 86, 140-149. [CrossRef]

52. Khan, S.; Beattie, T.K.; Knapp, C.W. The use of minimum selectable concentrations (MSCs) for determining the selection of antimicrobial resistant bacteria. Ecotoxicology 2017, 26, 283-292. [CrossRef] [PubMed]

53. Chen, Y.; Shen, W.; Wang, B.; Zhao, X.; Su, L.; Kong, M.; Li, H.; Zhang, S.; Li, J. Occurrence and fate of antibiotics, antimicrobial resistance determinants and potential human pathogens in a wastewater treatment plant and their effects on receiving waters in Nanjing, China. Ecotoxicol. Environ. Saf. 2020, 206, 111371. [CrossRef] [PubMed]

54. Topal, M.; Topal, E.I.A. Occurrence and fate of tetracycline and degradation products in municipal biological wastewater treatment plant and transport of them in surface water. Environ. Monit. Assess. 2015, 187, 750. [CrossRef] [PubMed] 
55. He, K. Occurrence of a Wide Range of Antibiotics, Estrogenic Hormones, and UV-Filters in Engineered and Natural Systems: Development of Analytical Methods and Investigation of Ecological Effects. Ph.D. Thesis, University of Maryland, Baltimore, MD, USA, 2017.

56. Fries, E.; Mahjoub, O.; Mahjoub, B.; Berrehouc, A.; Lions, J.; Bahadir, M. Occurrence of contaminants of emerging concern (CEC) in conventional and nonconventional water resources in Tunisia. Fresenius Environ. Bull. 2016, 25, 3317-3339.

57. Liu, H.; Lam, J.C.W.; Li, W.; Yu, H.; Lam, P.K.S. Spatial distribution and removal performance of pharmaceuticals in municipal wastewater treatment plants in China. Sci. Total Environ. 2017, 586, 1162-1169. [CrossRef]

58. Zhou, Y.; Meng, J.; Zhang, M.; Chen, S.; He, B.; Zhao, H.; Li, Q.; Zhang, S.; Wang, T. Which type of pollutants need to be controlled with priority in wastewater treatment plants: Traditional or emerging pollutants? Environ. Int. 2019, 131, 104982. [CrossRef] [PubMed]

59. Barbhuiya, N.H.; Adak, A. Determination of antimicrobial concentration and associated risk in water sources in West Bengal state of India. Environ. Monit. Assess. 2021, 193, 77. [CrossRef] 